\title{
Using SEVIRI fire observations to drive smoke plumes in the CMAQ air quality model: a case study over Antalya in 2008
}

\author{
G. Baldassarre ${ }^{1}$, L. Pozzoli ${ }^{1}$, C. C. Schmidt ${ }^{2}$, A. Unal ${ }^{1}$, T. Kindap ${ }^{1}$, W. P. Menzel $^{2}$, S. Whitburn ${ }^{3}$, P.-F. Coheur ${ }^{3}$, \\ A. Kavgaci ${ }^{4}$, and J. W. Kaiser ${ }^{5,6,7}$ \\ ${ }^{1}$ Eurasia Institute of Earth Sciences, Istanbul Technical University, Istanbul, Turkey \\ ${ }^{2}$ Cooperative Institute for Meteorological Satellite Studies, University of Wisconsin, Madison, WI, USA \\ ${ }^{3}$ Spectroscopie de l'Atmosphère, Service de Chimie Quantique et de Photophysique, Université Libre de Bruxelles (U.L.B), \\ Brussels, Belgium \\ ${ }^{4}$ Southwest Anatolia Forest Research Institute, Antalya, Turkey \\ ${ }^{5}$ King's College, London, UK \\ ${ }^{6}$ European Center for Medium-Range Weather Forecasts, Reading, UK \\ ${ }^{7}$ Max Planck Institute for Chemistry, Mainz, Germany
}

Correspondence to: G. Baldassarre (gi.baldassarre@gmail.com)

Received: 2 October 2014 - Published in Atmos. Chem. Phys. Discuss.: 6 January 2015

Revised: 15 June 2015 - Accepted: 13 July 2015 - Published: 30 July 2015

\begin{abstract}
Among the atmospheric emission sources, wildfires are episodic events characterized by large spatial and temporal variability. Therefore, accurate information on gaseous and aerosol emissions from fires for specific regions and seasons is critical for air quality forecasts. The Spinning Enhanced Visible and Infrared Imager (SEVIRI) in geostationary orbit provides fire observations over Africa and the Mediterranean with a temporal resolution of $15 \mathrm{~min}$. It thus resolves the complete fire life cycle and captures the fires' peak intensities, which is not possible in Moderate Resolution Imaging Spectroradiometer (MODIS) fire emission inventories like the Global Fire Assimilation System (GFAS). We evaluate two different operational fire radiative power (FRP) products derived from SEVIRI, by studying a large forest fire in Antalya, Turkey, in July-August 2008. The EUMETSAT Land Surface Analysis Satellite Applications Facility (LSA SAF) has higher FRP values during the fire episode than the Wildfire Automated Biomass Burning Algorithm (WF_ABBA). It is also in better agreement with the co-located, gridded MODIS FRP. Both products miss small fires that frequently occur in the region and are detected by MODIS. Emissions are derived from the FRP products. They are used along-side GFAS emissions in smoke plume simulations with the Weather Research and Forecasting (WRF) model and the Community Multiscale Air Quality (CMAQ)
\end{abstract}

model. In comparisons with MODIS aerosol optical thickness (AOT) and Infrared Atmospheric Sounding Interferometer (IASI), $\mathrm{CO}$ and $\mathrm{NH}_{3}$ observations show that including the diurnal variability of fire emissions improves the spatial distribution and peak concentrations of the simulated smoke plumes associated with this large fire. They also show a large discrepancy between the currently available operational FRP products, with the LSA SAF being the most appropriate.

\section{Introduction}

Fire is the main cause of forest destruction in countries of the Mediterranean basin (JRC, 2008), where the fire season starts in April and can last until the end of November. In terms of emissions, the biomass-burning contribution to $\mathrm{PM}_{2.5}$ was comparable with the anthropogenic contribution during recent years (e.g., Sofiev et al., 2009).

Emissions from open-vegetation burnings are increasingly recognized as an important parameter in atmospheric modeling, and their accurate description is important for specific regions and seasons as well as for specific episodes. Recent studies have demonstrated that open biomass-burning events, although episodic, may have important effects on the photochemistry in the eastern Mediter- 
ranean (Poupkou et al., 2014). Furthermore, the impact of biomass burning is expected to become more important in the southeastern Mediterranean according to future scenarios on climate change (Tolika et al., 2012; Migliavacca et al., 2013).

Continuous improvements of air quality models, such as the Community Multiscale Air Quality (CMAQ) model, permit simulation of the chemical composition of the atmosphere at fine spatial and temporal resolutions. Therefore, emission inventories must also be provided with a higher level of detail, and this is particularly important for forest fires, which are characterized by high spatial and temporal variations. According to Garcia-Menendez et al. (2014), in addition to adequate estimates of emitted mass, successfully modeling the impact of fires on air quality depends on an accurate spatiotemporal allocation of emissions.

Satellite remote sensing provides powerful means of locating and characterizing open-vegetation burnings. Infrared fire detection from satellites takes advantage of the fact that as target temperature increases radiance increases faster at the shortwave end of the spectrum when compared to the long-wave end. By using two atmospheric window spectral channels, such as the 3.9 and $11 \mu \mathrm{m}$, fire locations and characteristics can be determined. Since the cost of continuous monitoring of fires by ground and aircraft observations is prohibitive, monitoring with satellite observations offers a cost-effective alternative with broader coverage, especially in remote areas. While limited to cloud-free scenes, satellite observations can still provide a better understanding of fire issues.

Although designed for operational weather forecasting and not specifically for fire detection, the Spinning Enhanced Visible and Infrared Imager (SEVIRI) on board the Meteosat Second Generation (MSG) geostationary satellites shows great potential for fire detection and characterization. Since this instrument is employed on a geostationary platform, it can sample a large region with high temporal frequency (one observation per $15 \mathrm{~min}$ ). Under certain conditions (no opaque clouds, solar reflection, etc.) SEVIRI delivers important information on the temporal variability of active fires.

It has been demonstrated in small-scale experiments that the amount of radiant energy liberated per unit time during a vegetation fire, the so-called fire radiative power (FRP), is related to the rate at which the biomass fuel is being consumed. Spaceborne sensors that are able to observe the middle infrared (MIR) spectral radiance around $3.9 \mu \mathrm{m}$ emanating from the Earth can measure the radiative component of the energy released by open fires (Wooster et al., 2003). The estimate of biomass-burning emissions from FRP avoids using the complex parameters of fuel loading and burned area. Thus, it is a robust approach for the global estimates of biomass-burning emissions (e.g., Ichoku and Kaufman, 2005; Heil et al., 2010; Yang et al., 2011).

FRP has been successfully used to calculate biomass combusted from wildfires in Africa using measurements made by the SEVIRI on Meteosat- 8 (Roberts et al., 2005) and Moderate Resolution Imaging Spectroradiometer (MODIS) (Ellicott et al., 2009). Global examples are also available (Kaiser et al., 2009; Darmenov and da Silva, 2013).

Different satellite techniques have been developed using high temporal resolution multi-spectral data in order to detect and characterize fire activity. The Wildfire Automated Biomass Burning Algorithm (WF_ABBA) and the EUMETSAT Land Surface Analysis Satellite Applications Facility (LSA SAF) fire radiative power provide operational fire radiative power products based on SEVIRI observations using different algorithms.

In 2008 most of the large forest damage in Europe occurred in the southeastern Mediterranean countries, which were under the influence of extreme weather conditions conductive to fire ignition and spread. The country most heavily damaged was Turkey, where the forest fire danger was high during the period of May to October, and the period of July to September was especially active due to very high temperatures, very low humidity and effective winds. In Turkey, the coastline, which starts from Hatay and extends over the Mediterranean and Aegean up to Istanbul, has the highest fire risk. Approximately $60 \%$ (12 million ha) of Turkey's forest area is located in this fire sensitive area (JRC, 2009).

A large forest fire occurred on 31 July 2008 in Antalya, Turkey's most touristic province (Fig. 1). It burned for 5 consecutive days and affected 15795 ha of forestland mainly dominated by Turkish red pine (Pinus brutia Ten.), a typical fire adapted species of eastern Mediterranean basin ecosystems (Kavgaciet al., 2010). In this fire, many homes and farming buildings were destroyed. During the fire suppression efforts, 227 technical personal, 1680 fire fighters, 75 forest workers, 20 local managers, 1450 villagers and 80 gendarmes were employed. In those efforts, 197 fire suppression trucks with sprinklers, 45 bulldozers, 38 trailers, 5 road graders, 63 pickups, 9 helicopters and 7 planes were occupied.

In this paper, we investigate the applicability of the SEVIRI-based FRP products for air quality simulations with the CMAQ model, and compare to simulations based on the daily fire emissions derived from MODIS.

We calculate gridded FRP and emission inventories for a large region of the eastern Mediterranean during the life time of the Antalya fire using two operational SEVIRI FRP products. They are compared to the daily emission inventory based on MODIS at different spatial resolutions, $0.5^{\circ} \times 0.5^{\circ}$ (Global Fire Assimilation System - GFASv1.0), and $0.1^{\circ} \times$ $0.1^{\circ}$ (GFASv1.1). All four emission inventories are used as input in the CMAQ model. The simulated smoke plumes are then validated by comparison with the aerosol optical thickness (AOT) determinations from MODIS and $\mathrm{CO}$ and $\mathrm{NH}_{3}$ retrievals from Infrared Atmospheric Sounding Interferometer (IASI), which were previously used to track the emission and transport of pollution and to measure reactive trace 


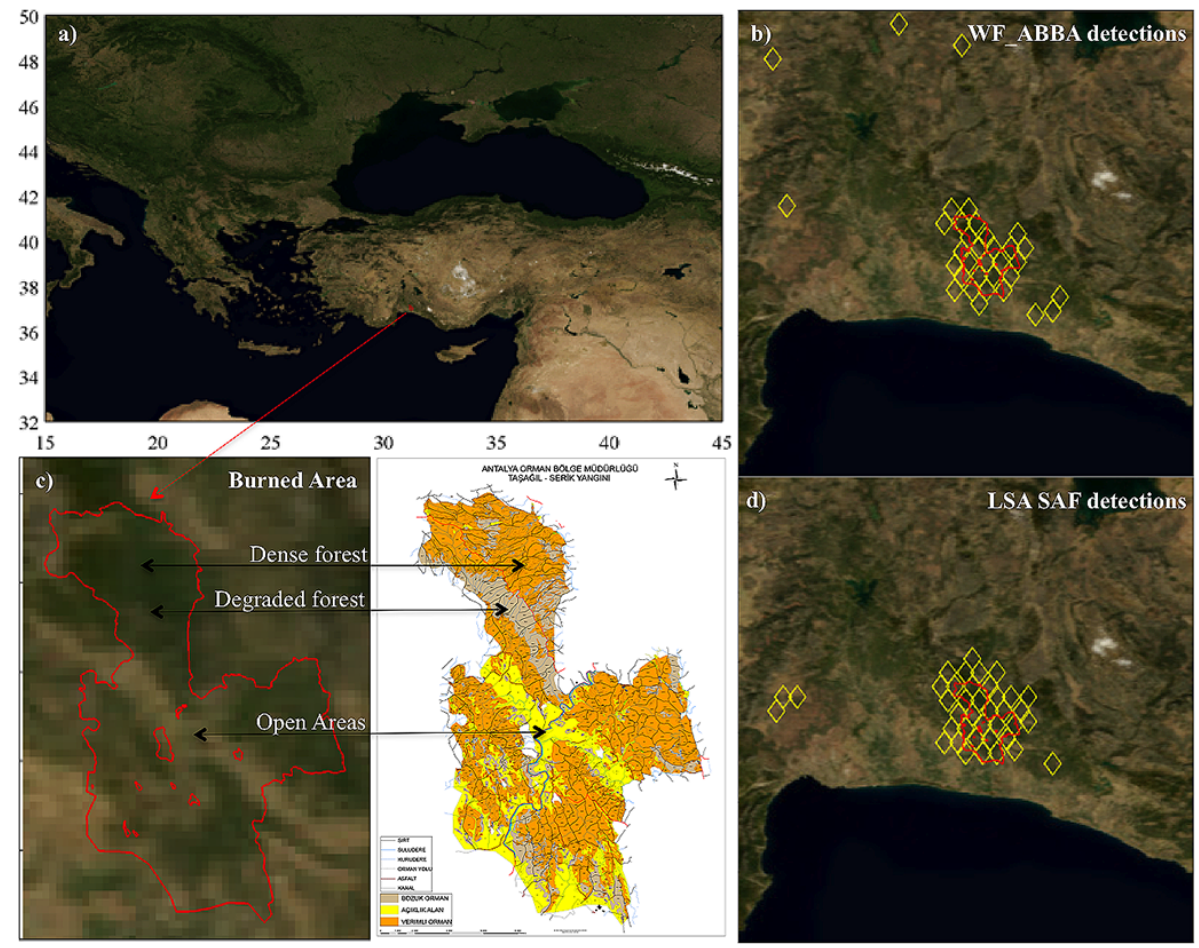

Figure 1. (a) Study area. (c) Burned area as reported by the Antalya forestry department (right) and over a MODIS Blue Marble image (left). (b) WF_ABBA (MSG-SEVIRI) detections of the Antalya fire. (d) LSA SAF (MSG-SEVIRI) detections of the Antalya fire.

species in biomass-burning plumes during the intense 2007 Greek forest fires (Turquety et al., 2009; Coheur et al., 2009).

\section{Methods}

\subsection{SEVIRI fire radiative power}

FRP is a measure of the radiant energy liberated per unit time from burning vegetation via the rapid oxidation of fuel carbon and hydrogen. Wooster et al. (2003) approximated FRP as the difference of the MIR spectral radiances between a fire pixel and ambient background pixels in a linear form. An alternative method uses the Dozier approximation of the instantaneous fire area and temperature (Dozier, 1981) to evaluate the FRP over the detected fire pixel by using thermal and middle infrared satellite observations.

Following the Wooster approach, the LSA SAF algorithm uses the SEVIRI band centered at $3.94 \mu \mathrm{m}$ infrared window to evaluate the FRP associated with the detected fire pixels, while the WF_ABBA uses a combination of both methods, depending on the availability of instantaneous area and temperature estimation over the detected fire pixel.

At the sub-satellite point, the field of view of the SEVIRI thermal channels is about $4.8 \mathrm{~km}$ with an overlap of $1.6 \mathrm{~km}$. The consequence of the overlap is that radiance coming from a single location is at times present in several neighboring pixels. Although this may not significantly impact other ap- plications, it is very important in the case of fire detection, since fires present complex geometric structures that make it difficult to identify the affected pixels (Calle et al., 2009). Also, the background temperature that is used in the FRP calculation is derived from neighboring pixels.

The $4 \mu \mathrm{m}$ channel of the SEVIRI sensor has a saturation temperature of $335 \mathrm{~K}$. Saturation of the SEVIRI pixels will not impact on the ability of the fire algorithms to detect fires, but it will lead to an underestimation of the true fire radiative power for large fires, which can contribute significantly to an underestimation of FRP.

The fire products described in this paper are derived using SEVIRI level 1.5 radiometrically calibrated and geometrically corrected imagery provided by the EUMETSAT LSA SAF. Resampling and regridding included in level 1.5 can act to mask the fire signal and impact both fire detection and characterization.

Previous studies have demonstrated that SEVIRI data can be used operationally to assist the detection of fires by improving the reliability in fire announcements (Laneve et al., 2006; Stoyanova et al., 2008) and enabling real-time fire front monitoring in southern Europe. The role of SEVIRI is especially useful as the fires increase in number and size (Sifakis et al., 2011). 


\subsection{Fire characterization data}

WF_ABBA is a dynamic contextual algorithm developed at the Cooperative Institute for Meteorological Satellite Studies (CIMSS) at the University of Wisconsin-Madison using multi-spectral Geostationary Operational Environmental Satellite (GOES) data to monitor biomass burning in the Western Hemisphere (Prins and Menzel, 1992, 1994; Prins, 2001). Recently a global version of the WF_ABBA (Version 6.5) has been applied to MSG-SEVIRI data. The global geostationary WF_ABBA Version 6.5.006 includes the following:

- fire mask indicating where fire detection is not possible: opaque cloud coverage; block-out zones due to solar reflectance, clouds, extreme view angles, biome type, bad data, etc.;

- revised ASCII fire product output: latitude; longitude; satellite view angle; pixel size; observed 4 and $11 \mu \mathrm{m}$ brightness temperatures; instantaneous estimates of fire size, temperature and FRP; biome type; fire confidence flag.

The Meteosat fire radiative power-pixel (FRP-pixel) product is derived at the Eumetsat LSA SAF (http://landsaf.meteo. pt/) at 15 min intervals using Meteosat SEVIRI observations. In this paper we often refer to this product only as LSA SAF (instead of using its full name LSA SAF FRP-pixel) in order to make its comparative analysis with other satellite products easier to read; in fact, just like the homologous WF_ABBA, the FRP is one type of information delivered by this product. The product is created using an operational version of the prototype geostationary active fire detection and characterization algorithm presented in Roberts and Wooster (2008). Most uses of the FRP-pixel product have so far been focused on Africa (e.g., Roberts et al., 2009), but the product also provides information on fires burning across Europe and parts of South America. The FRP-pixel product is freely available in near-real time or from the archive of the LSA SAF, and Wooster et al. (2015) and Roberts et al. (2015) fully described the operational version of the product, its content and use. For each processed region, the FRP-pixel algorithm generates two output files.

- FRP quality flag: this file provides the actual status of each pixel in the selected region, whether it contains a detected fire or not, and a number of other conditions such as whether the pixel is cloudy or in clear sky, coastline, etc. (Lattanzio et al., 2009).

- FRP list: one entry for every fire pixel that has an estimated FRP value. For each fire pixel, the FRP and an exhaustive list of relevant information such as the fire pixel background window mean temperature is also provided.
Due to the higher spatial resolution and wide usage of the MODIS active fire products, these are taken to be the reference standard against which the SEVIRI FRP product is assessed.

The Global Fire Assimilation System version 1.1 calculates biomass-burning emissions by assimilating FRP observations from the MODIS instruments onboard the Terra and Aqua satellites. It provides daily emissions on a global $0.1^{\circ} \times 0.1^{\circ}$ grid .

The comparison of SEVIRI FRP to GFAS emissions should be regarded as a comparison between two independent data sets rather than a validation using a reference data set (Schultz and Wooster, 2008).

\subsection{Emission inventory}

\subsubsection{WF_ABBA-LSA SAF gridding at 0.1 regular grid}

In order to create a fire emission inventory at the same grid of GFASv1.1, we started from WF_ABBA and LSA SAF FRP-pixel products and generated a gridded FRP product at $0.1^{\circ} \times 0.1^{\circ}$ resolution containing area integrated FRP totals corrected for partial cloudiness at the grid cell scale.

The gridding method is described in Govaerts et al. (2007). The FRP derived from the SEVIRI image (LSA SAF and WF_ABBA) acquired at time $t$ are summed over a regular grid of resolution $\mathrm{G}^{\circ} \times \mathrm{G}^{\circ}$ grid box. For each grid point $\left(X_{\mathrm{G}}\right.$, $Y_{\mathrm{G}}$ ), the total FRP is

$\operatorname{FRP}\left(t, i_{\mathrm{G}}, j_{\mathrm{G}}\right)=\frac{1}{f_{\mathrm{s}}\left(t, i_{\mathrm{G}}, j_{\mathrm{G}}\right)} \sum_{\left(i_{t}, j_{t}\right) \in \mathrm{G}^{\circ} \times \mathrm{G}^{\circ}} \operatorname{FRP}\left(t, i_{f}, j_{f}\right)$,

where $f_{\mathrm{s}}\left(t, i_{\mathrm{G}}, j_{\mathrm{G}}\right)$ is the fraction of clear-sky pixels ${ }^{1}$ over land within the $\mathrm{G}^{\circ} \times \mathrm{G}^{\circ}$ grid box. When $f_{\mathrm{s}}<0.2$ the equation is not estimated. $\left(i_{f}, j_{f}\right) \in \mathrm{G}^{\circ} \times \mathrm{G}^{\circ}$ means that the center of SEVIRI pixel $\left(i_{f}, j_{f}\right)$ is inside the new grid $\mathrm{G}^{\circ} \times \mathrm{G}^{\circ}$. We average the gridded FRP over $1 \mathrm{~h}$ time period. As a consequence, the SEVIRI-based fire emission inventories will have hourly time resolution, in contrast with MODIS, and reveal diurnal patterns.

\subsubsection{Emission factors for WF_ABBA and LSA SAF}

The GFAS emission inventory represents our reference information on biomass-burning activity over the eastern Mediterranean domain. In order to make our SEVIRI FRPbased fire emission inventory comparable with this data set we followed a similar procedure as described in Kaiser et al. (2012), then we can evaluate emission rates of main biomass-burning pollutants calculated from WF_ABBA and

\footnotetext{
${ }^{1}$ We used the WF_ABBA fire mask and LSA SAF quality flag products to have information about the status of each processed pixel in the selected region (block-out zones due to solar reflectance, clouds, extreme view angles, biome type, bad data, etc.).
} 
Table 1. Total particulate matter estimates [tons] in the study area and for Antalya fire from WF_ABBA and LSA SAF FRP-pixel products during Antalya fire lifetime (31 July and 5 August 2008), using conversion factors and emission coefficients described in Kaiser et al. (2012) (referring to Andreae and Merlet, 2001) boosted by 3.4 and Ichoku and Kaufman (2005) smoke emission coefficients. The estimates based on Ichoku and Kaufman (2005) are set in italics below the ones referring to Andreae and Merlet (2001).

\begin{tabular}{lrr}
\hline & Turkey & Antalya fire \\
\hline WF_ABBA & 29411.9 & 3967.1 \\
& 158894.5 & 10559.1 \\
\hline LSA SAF & 48090.6 & 18992.3 \\
& 199287.6 & 50551.8 \\
\hline
\end{tabular}

LSA SAF FRP-pixel fire characterization data. This approach also helps to investigate differences between the three biomass-burning emission inventories over the case study area and over the Antalya fire itself.

The hourly FRP gridded product was converted to major contaminant emission rate using conversion factors to dry matter combustion rate and emission factors based on an updated version of the compilation by Andreae and Merlet (2001).

Using satellite retrievals and top-down estimates of particulate matter, Kaiser et al. (2012) concluded that emissions of particulate matter calculated with this method need to be boosted to reproduce the global distribution of organic matter and black carbon. Thus, in this work, we used the proposed aerosol enhancement factor of 3.4.

An alternative approach to estimate biomass-burning smoke aerosols is to directly relate them to FRP, using smoke emission coefficients $\left[\mathrm{kg} \mathrm{MJ}^{-1}\right]$ proposed by Ichoku and Kaufman (2005). Specifically, the values we assign to the main land cover types are $0.06 \mathrm{~kg} \mathrm{MJ}^{-1}$ for savannah and tropical forest, $0.084 \mathrm{~kg} \mathrm{MJ}^{-1}$ for agriculture and $0.02 \mathrm{~kg} \mathrm{MJ}^{-1}$ for extra tropical forest. Table 1 shows a significant difference between smoke aerosol emissions evaluated with this approach and with the one described in Kaiser et al. (2012) already boosted by the aerosol enhancement factor. We use the approach of Kaiser et al. (2012) in this work to simulate the atmospheric composition of Antalya fire with the CMAQ air quality model.

\subsubsection{Vertical distribution}

Vertical distribution of fire emission is critical for air quality simulation in presence of energetic wild fire episodes as the plume top height can strongly exceed the daily maximum of the boundary layer height. Below this height, fast turbulent mixing rapidly redistributes the emissions through out the boundary layer.

The emissions calculated for each hour were vertically distributed within all layers in proportion to their thickness com- pared to plume height, determined by using a semi-empirical formula suggested by Sofiev et al. (2012).

This methodology is based on three input parameters: boundary layer height, Brunt-Väisälä frequency in the free troposphere and fire radiative power. The first two parameters are derived by the meteorological conditions evaluated at each fire using output from the WRF meteorological simulation, and the 15 min resolution FRP in the Sofiev formula means that a correct estimation of the diurnal cycle of the fire, crucial for a correct vertical allocation of the fire emissions, will be incorporated.

\subsection{Meteorological and air quality modeling}

A series of model simulations were performed to reproduce the chemical composition of the atmosphere during the selected episode using the Advanced Research Weather Research and Forecasting model (WRF-ARW v3.3; Skamarock and Klemp, 2008; http://wrfmodel.org/) and the CMAQ model (CMAQv4.7.1; Foley et al., 2010). The WRF-ARW model is widely used and its ability to reproduce the meteorological conditions, including the region of interest (the eastern Mediterranean basin) has been proven in previous studies (e.g., Im et al., 2010, 2011). The operational temperature, wind, humidity and pressure fields retrieved from the European Center for Medium-Range Weather Forecasting (ECMWF) model with $0.25^{\circ} \times 0.25^{\circ}$ lat-long horizontal resolution and 6-hourly temporal resolution were used to constrain the WRF meteorological simulation through nudging, initial and boundary conditions. The following physical options in the WRF meteorological simulations were used: WSM3 microphysics scheme (Hong et al., 2004), RRTM (rapid radiative transfer model) long-wave radiation scheme (Mlawer et al., 1997), Dudhia shortwave radiation scheme (Dudhia, 1989), NOAH land surface model (Chen and Dudhia, 2001), Yonsei University planetary boundary layer (PBL) scheme (Hong and Lim, 2006) and Kain-Fritsch cumulus parameterization scheme (Kain, 2004).

CMAQ is a regional air quality model widely used to simulate the atmospheric composition of the atmosphere (Hogrefe et al., 2001; Unal et al., 2005; Kindap et al., 2006; Odman et al., 2007; Im et al., 2010, 2011). The MeteorologyChemistry Interface Processor (MCIPv3.6, Otte and Pleim, 2010) was used to process the WRF meteorological output for the CMAQ simulations. The Carbon Bond-V (CB05) chemical mechanism (Yarwood et al., 2005) and the AERO5 module (Foley et al., 2010) were used for the gas-phase chemistry and aerosol and aqueous chemistry, respectively.

The WRF-CMAQ model simulations were performed for two nested domains. The coarse domain has a resolution of $30 \mathrm{~km} \times 30 \mathrm{~km}(192 \times 160$ cells $)$ and covers all of Europe. The fine domain has the resolution of $10 \mathrm{~km} \times 10 \mathrm{~km}(186 \times 156$ cells), centered in the Marmara Sea region including southern Turkey (see Fig. S1 in the Supplement), where the fire episode occurred close to Antalya; 24 vertical layers, from 
surface to about $26 \mathrm{~km}$, are used for both domains; the layer thickness increases from surface to the top, and the first eight levels have a spacing of $\approx 100 \mathrm{~m}$. The initial chemical concentrations and boundary conditions for the coarse domain were provided from the Monitoring Atmospheric Composition and Climate (MACC) data service, which provide a comprehensive reanalysis of atmospheric composition for the period 2003-2010 (http://gmes-atmosphere.eu/; Inness et al., 2013), while the output of the coarse domain was used to create initial concentrations and boundary conditions for the nested domain.

The Netherlands Organization for Applied Scientific Research (TNO)/MACC_2005 emission inventory (Denier van der Gon et al., 2005) was used for anthropogenic sources of the main gaseous and aerosol atmospheric pollutants $(\mathrm{CO}$, $\mathrm{NO}_{\mathrm{x}}, \mathrm{SO}_{2}, \mathrm{NMVOC}, \mathrm{NH}_{3}, \mathrm{PM}_{2.5}$ and PMcoarse). The emissions from vegetation, biogenic volatile organic compounds (BVOC; e.g., isoprene and terpenes) were estimated using the Model of Emissions of Gases and Aerosols from Nature (MEGAN; Guenther et al., 2006) according to the simulated temperature and radiation fields from the meteorological model. Sea salt aerosol emissions are calculated online by CMAQ model as a function of wind speed (Kelly et al., 2009). Mineral dust emissions were not included in this study; nevertheless during the studied episode dust outbreaks from North Africa and Arabian Peninsula were not forecasted over the Mediterranean Sea and southern Turkey (not shown; BSC-DREAM8b v1.0; http://www.bsc. es/earth-sciences/mineral-dust/catalogo-datos-dust); therefore, the impact of mineral dust on PM concentrations can be neglected.

Different emission inventories were used and created to describe the Antalya wildfire episode, and used in the WRFCMAQ simulation.

The air quality simulations are first performed without fire emission information on both reference domains. The GFAS1.0 inventory (Kaiser et al., 2012) is used to provide biomass-burning emission information over the coarse domain (covering all Europe). The WRF/CMAQ simulations at $30 \mathrm{~km} \times 30 \mathrm{~km}$ are used to provide boundary and initial conditions to the fine resolution simulations. For the simulations at $10 \mathrm{~km} \times 10 \mathrm{~km}$ horizontal resolution, the more refined GFAS1.1 emission inventory represents the reference information on biomass-burning activity over the eastern Mediterranean domain, which is compared with two newly developed high temporal resolution emission inventories based on FRP derived by SEVIRI data with two different algorithms, WF_ABBA and LSA SAF.

All the CMAQ simulations consider only black carbon (BC) and organic carbon (OC) (Morcrette et al., 2007) for the smoke aerosol emissions. The total organic matter (OM) emitted is calculated by scaling OC emissions by a factor of 1.5 .

\subsection{Satellite observations}

\subsubsection{MODIS aerosol optical thickness}

As a source of information on the aerosol content in the atmosphere over the area affected by the Antalya fire at the beginning of August 2008, we used the MODIS Aerosol Product. This satellite product reproduces the ambient AOT over the oceans globally and over a portion of the continents Remer et al., 2005; Levy et al., 2007.

The MODIS instrument has near-daily global coverage with a swath width of $2330 \mathrm{~km}$.

We collect MODIS AQUA level 2 aerosol products, collection 5.1 (MOD04, LAADS Web-NASA). This product provides AOT data at $0.55 \mu \mathrm{m}$ with a spatial resolution of $10 \mathrm{~km}^{2}$.

The MODIS data often contain large areas of missing values, especially during the fires, due to the presence of clouds, the presence of fire plumes in clouds and misclassification of fire plumes as clouds (Yang et al., 2011).

\subsection{2 $\mathrm{CO}$ and $\mathrm{NH}_{3}$ from IASI}

The IASI, the first of a series of three, is a passive remote sensing instrument operating in nadir mode circling in a polar sun-synchronous orbit on board the MetOp-A (Meteorological Operational) satellite. IASI provides a twice-daily global coverage of the Earth surface (9:30 and 21:30 LT) with a relatively small footprint on the ground (circular pixel with $12 \mathrm{~km}$ diameter at nadir) (Coheur et al., 2009). Its large and continuous spectral coverage of the infrared region (645$\left.2760 \mathrm{~cm}^{-1}\right)$, combined with a medium spectral resolution $\left(0.5 \mathrm{~cm}^{-1}\right.$ apodized) and a low instrumental noise $(\approx 0.2 \mathrm{~K}$ at $950 \mathrm{~cm}^{-1}$ and $280 \mathrm{~K}$ ) (Clerbaux et al., 2009), allow the atmospheric concentrations of a variety of atmospheric constituents to be measured (Coheur et al., 2009; Clarisse et al., 2011), including carbon monoxide and ammonia, both emitted in large amounts by vegetation fires.

Total columns of CO are from the FORLI (Fast-Optimal Estimation Retrievals on Layers for IASI) near real-time retrieval software (Hurtmans et al., 2012). The retrieval is based on the optimal estimation method (OEM) described by Rodgers (2000). It minimizes, by iteratively updating a state vector (set of unknown parameters), the difference between an observed and a simulated spectrum, using constrains defined by an a priori profile (averaged value expected, $x_{\mathrm{a}}$ ) and its variability (covariance matrix $\mathbf{S}_{\mathrm{a}}$ ), which represent our best knowledge of the system (Turquety et al., 2009).

Total column $\mathrm{NH}_{3}$ is retrieved from IASI using the algorithm of Van Damme et al. (2014), which is built on the detection method described by Walker et al. (2011). The retrieval scheme includes two steps. First a so-called hyperspectral range index (HRI) is calculated from each spectrum measured by IASI. The HRI is then converted into $\mathrm{a} \mathrm{NH}_{3}$ to- 

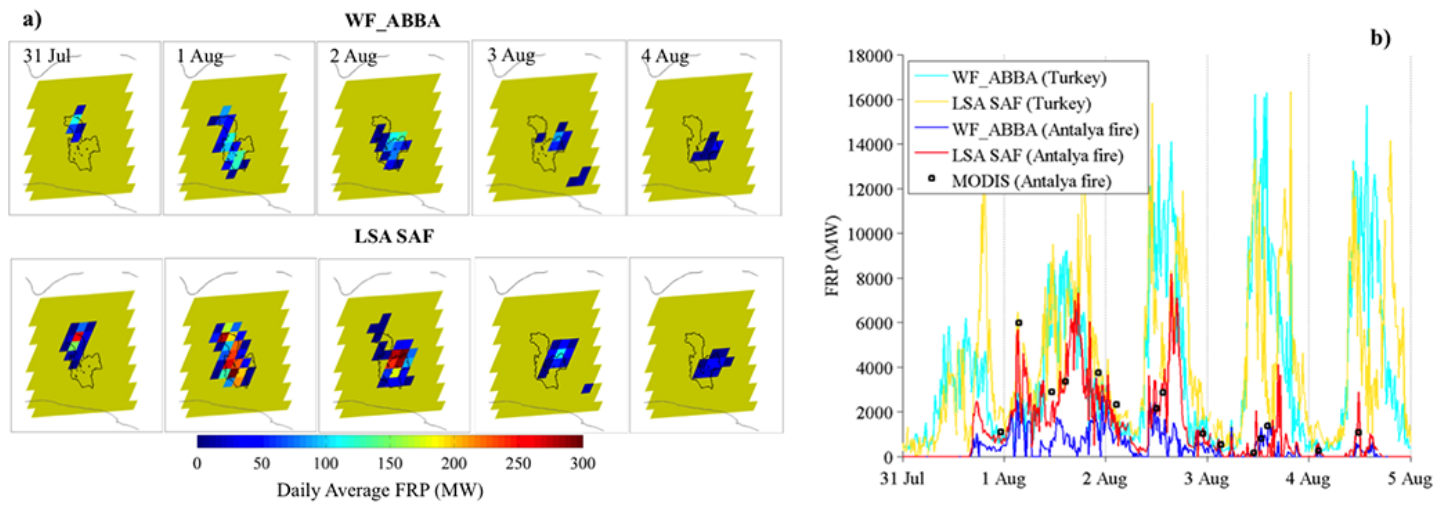

Figure 2. (a) Daily average FRP (MW) over the Antalya fire. (b) Total fire radiative power (FRP) detected over the eastern Mediterranean and over the Antalya fire between 30 July 2008 and 6 August 2008. The data are derived from the WF_ABBA and LSA SAF. Open black squares indicate the FRP observed over the area of the Antalya fire at a lower temporal resolution by the two MODIS instruments.

tal column using look-up tables of HRI built from simulated spectra under various atmospheric conditions.

The daily average total column for $\mathrm{NH}_{3}$ has been calculated using the weighted averaging method as follows (Van Damme et al., 2014):

$$
\bar{X}=\frac{\sum \omega_{i} x_{i}}{\sum \omega_{i}}
$$

where $\omega=1 / \sigma^{2}$ and $\sigma$ is the relative error on the retrieved column.

\section{Results: wildfire emission inventories}

\subsection{What SEVIRI sees}

SEVIRI captured biomass-burning activities in the province of Antalya from their beginning, as confirmed by ground reported observations, in the early afternoon of the 31 July and monitored the entire lifetime of the fire till the end on $5 \mathrm{Au}$ gust 2008 .

The Antalya fire was an extreme event in terms of energy output. Figure 2a shows the spatiotemporal evolution of the biomass burning in terms of daily average FRP as estimated by WF_ABBA and LSA SAF fire algorithms using SEVIRI observations.

In Fig. $2 b$ the estimated FRPs, based on SEVIRI observations, over the study area and over Antalya fire between 30 July and 6 August 2008, are depicted. (The timescale for all the results is in local time (LT) which is more easily linked to the diurnal cycle of the fires.) In the same graph we can also see the FRP observed by MODIS over the Antalya fire.

The graph reveals the pronounced diurnal fire cycle driven by day/night differences in atmospheric humidity, temperature and wind. However, during the second day of the Antalya fire, the nocturnal activity was also very strong. We notice that the first part of the event (from 31 July to $3 \mathrm{Au}$ - gust 2008) was particularly intense, reaching FRP values of 8000 MW (according to LSA SAF FRP-pixel product).

The two SEVIRI-based FRP products depict the same fire episode differently (Fig. 2). The WF_ABBA data produces lower emission estimates than those generated from LSA SAF during the intense fire period of 31 July to $1 \mathrm{Au}-$ gust, while both products are comparable when only smaller fires are present. Differences between the two algorithms, particularly in their handling of pixel oversampling, could explain why the difference is largest during peak burning.

MODIS observations, when available, show greater consistency with the LSA SAF product. But, due to its dependence on the scheduled day overpass of EOS AQUA and TERRA, this instrument could not observe the two most intense moments of the fire activity, both in the afternoon of 1 and 2 August 2008.

The agreement between MODIS and LSA SAF suggests that the WF_ABBA is performing less well, particularly considering that the WF_ABBA FRP consistently appears to be lower than LSA SAF FRP. However, the WF_ABBA detections matched the fire perimeter more closely, indicating it handles the diffraction due to the point spread function more effectively. The apparently low FRP values from the WF_ABBA may reflect an issue with the algorithm, including missed fire pixels that may have been screened out by overly aggressive cloud screening for example, over counting by LSA SAF, or a combination of both. An additional factor could be the difference in dynamic range between MODIS and SEVIRI and how the WF_ABBA and LSA SAF handle saturated fire pixels.

\subsection{Magnitude of fire emissions over the eastern Mediterranean basin and over the Antalya fire}

The hourly and daily average total particulate matter (TPM) emission rates, integrated over the study area and over the Antalya fire, from 30 July to 6 August 2008, are presented 

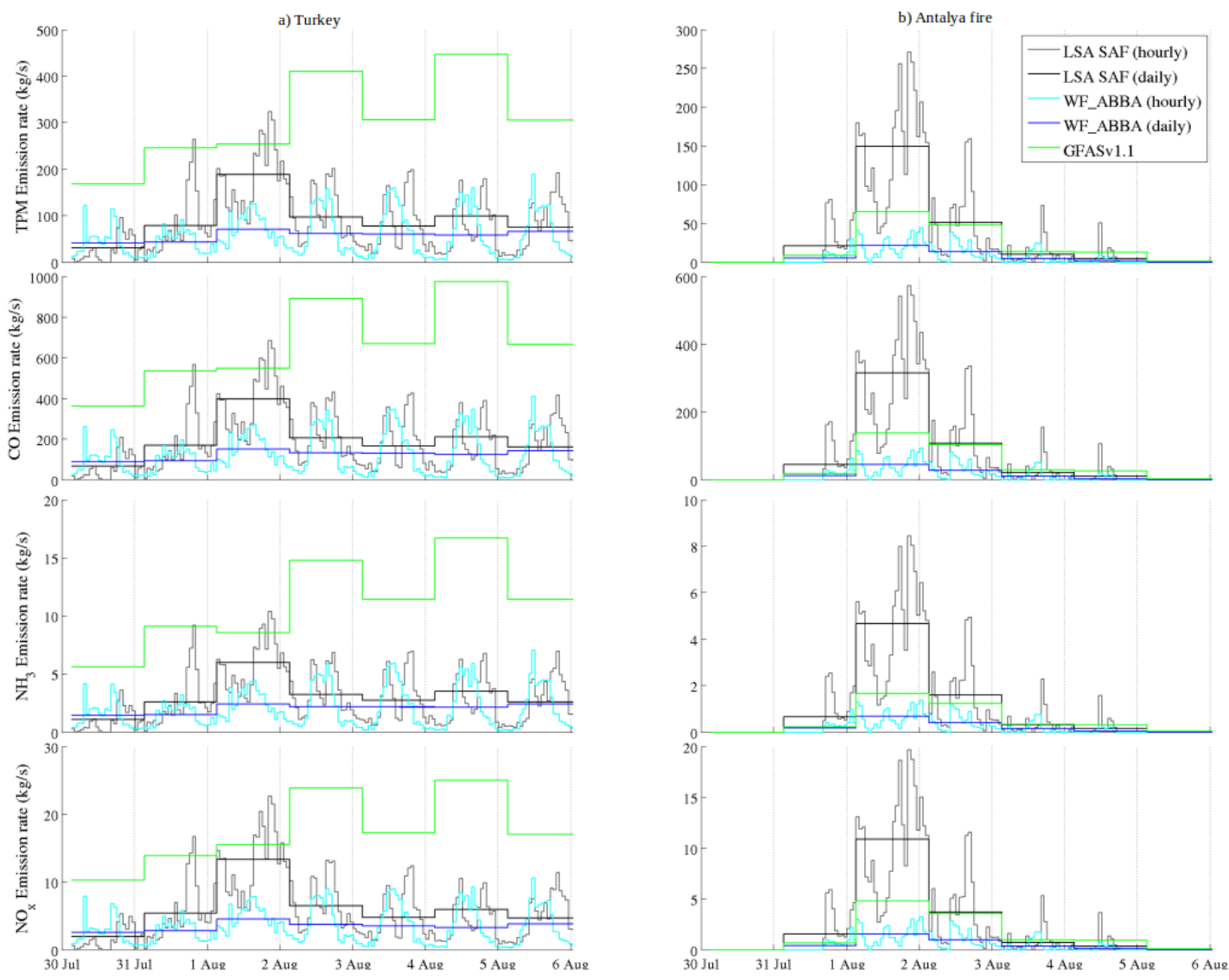

Figure 3. TPM, $\mathrm{CO}, \mathrm{NH}_{3}$ and $\mathrm{NO}_{x}$ emission rates observed over the eastern Mediterranean (a) and over the Antalya fire (b) from 30 July to 6 August 2008. Cyan and blue lines are the hourly and daily WF_ABBA FRP. Grey and black lines are the hourly and daily LSA SAF FRP-pixel. Green line is the GFASv1.1.
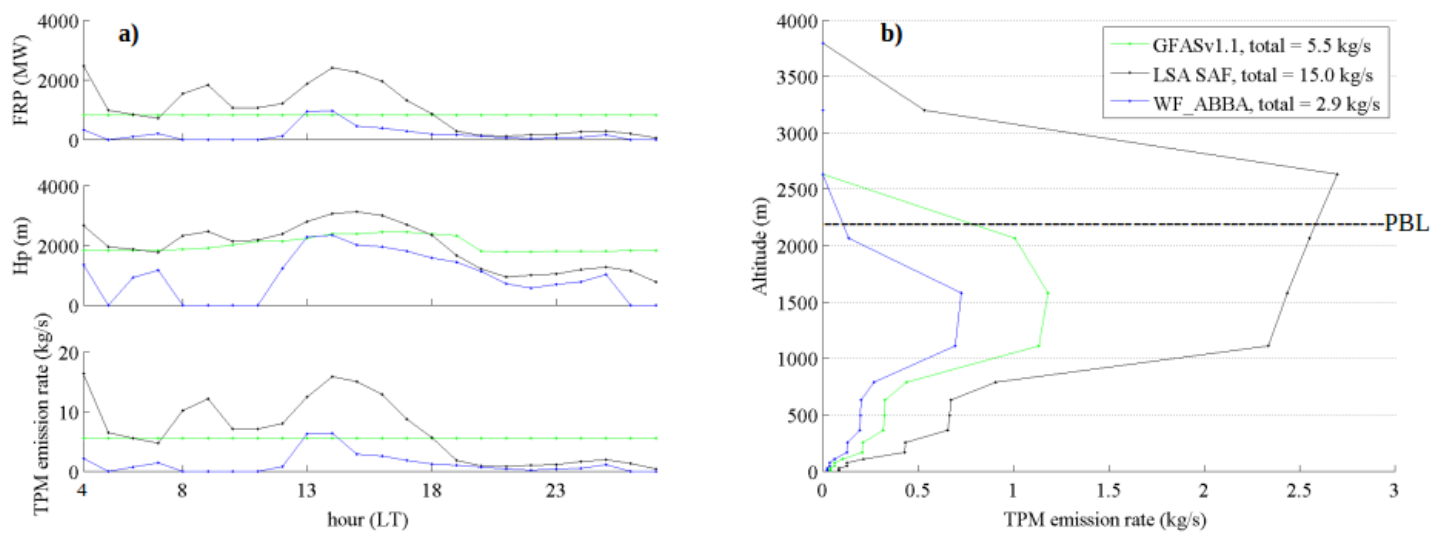

Figure 4. (a) Temporal variation of FRP, plume injection height (Hp) and TPM emission rate for a strong emitting fire pixel in the model grid belonging to the Antalya fire on 1 August 2008. (b) Vertical distribution of $\mathrm{PM}_{2.5}$ emission rate over the same pixel at 15:00 LT of the same day. The black-dashed line defines the PBL.

in Fig. 3. They are plotted together with the GFASv1.1 (in green) over the same areas and time period.

For the entire region, GFASv1.1 emission estimation is significantly higher than the SEVIRI-based WF_ABBA and LSA SAF FRP-pixel products. For the Antalya fire area, the comparison is closer; the LSA SAF FRP-pixel-based emission estimations are the highest (Fig. $3 \mathrm{~b}$ and Table 2).

Differences between GFASv1.1 and SEVIRI-based (WF_ABBA and LSA SAF) fire-induced emissions estimates, when they are integrated over the study area, are 
Table 2. Total fire emission estimates of the principal pollutants [tons] in the study area and for Antalya fire from WF_ABBA and LSA SAF FRP-pixel products and GFASv1.1 during Antalya fire lifetime (31 July and 5 August 2008). The GFASv1.1 values are italic below the value for WF_ABBA and LSA SAF FRP-pixel (in bold) based ones.

\begin{tabular}{lrr}
\hline Species & Turkey & Antalya fire \\
\hline $\mathrm{CO}$ & 63338.5 & 8373.4 \\
& $\mathbf{1 0 2 6 1 3 . 0}$ & $\mathbf{4 0 0 8 7 . 6}$ \\
& 370204.9 & 27279.7 \\
\hline $\mathrm{NMHC}$ & 5710.3 & 466.7 \\
& $\mathbf{7 6 4 5 . 7}$ & $\mathbf{2 2 3 4 . 4}$ \\
& 37019.9 & 1513.1 \\
\hline $\mathrm{NO}_{\mathrm{x}}$ & 1782.7 & 288.3 \\
& $\mathbf{3 1 8 1}$ & $\mathbf{1 3 8 0 . 1}$ \\
& 9721.4 & 942.4 \\
\hline $\mathrm{PM}_{2.5}$ & 18817.5 & 2286.9 \\
& $\mathbf{2 9 3 7 1 . 4}$ & $\mathbf{1 0 9 4 8 . 5}$ \\
& 111233.7 & 7448.2 \\
\hline $\mathrm{OC}$ & 10394.2 & 1493.5 \\
& $\mathbf{1 7 5 0 7 . 1}$ & $\mathbf{7 1 5 0}$ \\
& 58115.2 & 4846.2 \\
\hline $\mathrm{BC}$ & 1193.8 & 214.7 \\
& $\mathbf{2 2 5 0 . 6}$ & $\mathbf{1 0 2 7 . 8}$ \\
& 6267 & 697.5 \\
\hline $\mathrm{SO}_{2}$ & 300.3 & 50.8 \\
& $\mathbf{5 4 8 . 4}$ & $\mathbf{2 4 3 . 2}$ \\
& 1586.6 & 163.2 \\
\hline & 1045.6 & 243.2 \\
& $\mathbf{1 6 1 2 . 1}$ & $\mathbf{5 9 1 . 5}$ \\
& 6211.3 & 326.6 \\
\hline & & \\
& &
\end{tabular}

mainly due to the presence of agricultural waste burning, common this time of the year in eastern Europe. In fact, the coarse spatial resolution of SEVIRI results in numerous low intensity fires ${ }^{2}$ being undetected.

On the other hand, the impact of coarse spatial resolution is balanced by the very high temporal resolution of the geostationary observations. Thus, SEVIRI captures the complete Antalya fire life cycle which the much higher spatial resolution MODIS instruments on EOS Aqua and Terra are unable to describe with their 4 times per day overpasses.

The large differences in daily values found in Fig. 3 are also seen in Fig. S2, in the Supplement. This figure shows a large presence of low energy fire pixels (daily

\footnotetext{
${ }^{2}$ Minimum FRPs returned by the fire detection algorithm when applied to real SEVIRI Level 1.5 data are on the order of $\approx 40 \mathrm{MW}$ (and at extreme $\approx 20 \mathrm{MW}$ ) at the sub-satellite point. For MODIS, the minimum FRP detection threshold for reliably detected fire pixels is $\approx 7-10 \mathrm{MW}$ (Schultz and Wooster, 2008).
}

FRP $<20 \mathrm{MW}$ ) over eastern Europe depicted by GFASv1.1 during 1 August 2008 (daily FRP integrated over the entire region, excluding the Antalya fire, $\approx 14.4 \mathrm{GW}$ ). During the same day, the WF_ABBA and LSA SAF describe a reduced fire activities (daily FRP integrated over the entire region, excluding the Antalya fire, $\approx 3.4$ and $\approx 2.4 \mathrm{GW}$, respectively), especially in eastern Europe where the SEVIRI spatial resolution is larger (due to scan angle effects).

On the other hand, if we reduce our study area only to the region surrounding the Antalya fire, the LSA SAF estimates a daily FRP more than double $(6.6 \mathrm{GW})$ that of the GFASv1.1 (2.9 GW); GFASv1.1 only used 4 MODIS observations over the area affected by the fire, despite the 96 available from SEVIRI which captured the peak of the burning.

\subsection{Temporal and spatial allocation of the fire emissions}

A recent study by Garcia-Menendez et al. (2014) has shown that, in addition to adequate estimates of emitted mass, horizontal and vertical distributions of emissions in gridded domains and their timing are key inputs to successfully model the impacts of fires on air quality. According to the same study the largest potential gains related to depiction of firerelated emissions lie in better characterizing their temporal distribution. The same analysis demonstrated that the fire emission allocated to each hour produces a response at downwind receptors lasting $2-3 \mathrm{~h}$, concluding that better approximation of the timing and progression of fire-related emissions is a viable approach to improve model performance.

Figure 4a shows the hourly variation of FRP, plume injection height ( $\mathrm{Hp}$ ) (as defined by the Sofiev formula) and $\mathrm{PM}_{2.5}$ emission rates on 1 August 2008, for a strong fire pixel in the model grid, belonging to the Antalya fire, as estimated by the three different fire emission inventories.

Looking at this figure, we can appreciate the more accurate temporal allocation of the fire emission achieved by using SEVIRI FRP data. Both SEVIRI-based algorithms describe peak emissions at 04:00 LT, and around 14:00 LT, a secondary maximum around 07:00 LT for WF_ABBA and 09:00 LT for LSA SAF, and much less intense fire activity after 18:00 LT.

The vertical allocation of the $\mathrm{PM}_{2.5}$ emission rate for the same fire pixel at 15:00 LT is shown in Fig. 4b. Refinement in the emission inventory, achieved by using the improved temporal resolution of the SEVIRI FRP data, leads to a different vertical allocation. In fact, the FRP is one of the parameters used to evaluate the hourly vertical distribution of the fire emissions. For example, according to the LSA SAF fire characterization, at 15:00 LT of 1 August on the fire pixel selected in Fig. 4, the fire activity became very strong and ejected a large quantity of particulate matters above the PBL. We notice from Fig. 4a that the GFAS hourly injection height is not constant during the day. In fact, even if the pixel-based GFAS FRP does not change in a daily time frame, the other param- 


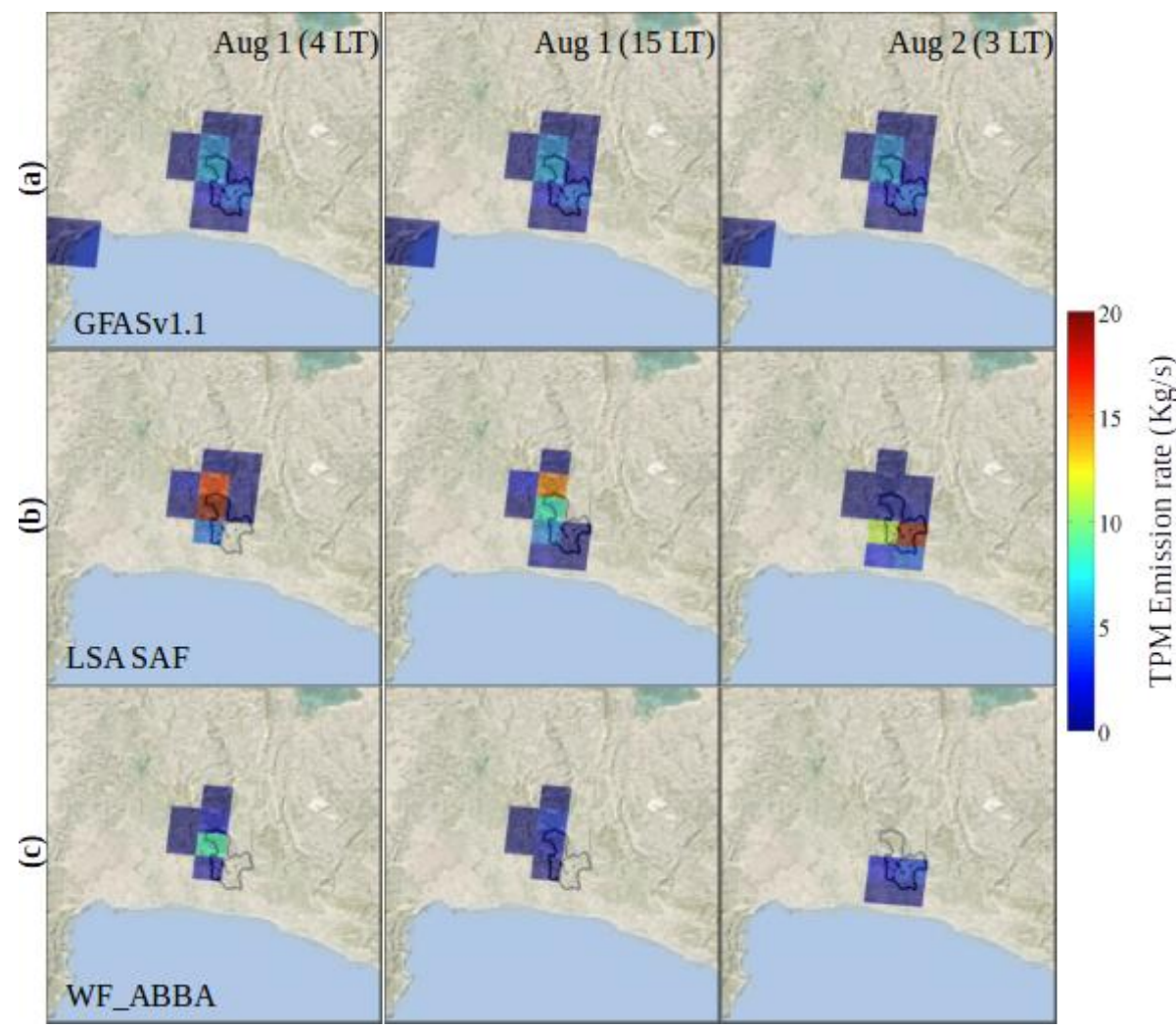

Figure 5. Horizontal allocation of the Antalya fire emitting pixels during 1 August 2008 as derived by GFASv1.1 (a), LSA SAF (b) and WF_ABBA (c) FRP-based fire emission inventories. Black line is the ground reported burned area (on the upper-right corner of this picture, 03:00 LT of 2 August means 24:00 UTC of 1 August).

eters used to calculate this information in the Sofiev formula are driven by meteorological conditions that are changing hourly.

Previous studies have shown that vertical mixing of fire emission within the PBL is rapid, while correctly determining plume penetration into the free atmosphere is critical (Garcia-Menendez et al., 2014; Konovalov et al., 2014).

Figure 5 shows the horizontal allocation of the TPM fire emission at the beginning, middle and end of the most intense day of the Antalya fire.

In the presence of large wildfires, the horizontal allocation of the emissions also becomes critical, because these fires can travel over a vast area and affect different pixels within the model domain during the same day. In fact, as we can see from SEVIRI-based TPM emission rate in Fig. 5b and c during 1 August, the Antalya fire moved from the northwest border of the ground reports of the burned area to the southeast (see also Fig. 2a), emitting aerosols at different emission rates in the pixels of the model grid affected by the burning during the day. This level of description of the horizontal allocations of the fire emission cannot be achieved with the daily GFASv1.1 (Fig. 5a).

Garcia-Menendez et al. (2014) demonstrated that model performance could benefit from more accurately positioning emissions. In fact the responsiveness of simulated fire pollutant concentrations to small variations in the horizontal allocation of fire emissions also reflects a strong influence from meteorological inputs.

\section{Results: air quality model simulations}

\subsection{Smoke plume simulations}

During the most intense period of the Antalya fire, winds over the study area were mostly southerly and they transported the smoke from the fires to the Mediterranean Sea. Figure 6 shows the smoke plume on 1 August 2008 at 14:30 LT from the Antalya fire in MODIS visible imagery (Fig. 6a) and in the MODIS level 2 aerosol optical thickness product (Fig. 6b). We note that the MODIS AOT data contain large areas of missing values (see also Fig. S3a in the Supplement), probably due to misclassification of fire plumes as clouds. In fact, these retrievals are obtained by aggregating information from $1 \mathrm{~km}$ pixels (see Levy et al., 2007). Probably, in this case, the AOD algorithm labels the pixels with the strongest smoke aerosol concentration (right below the bay of Antalya) as clouds and performs the AOD retrieval in 


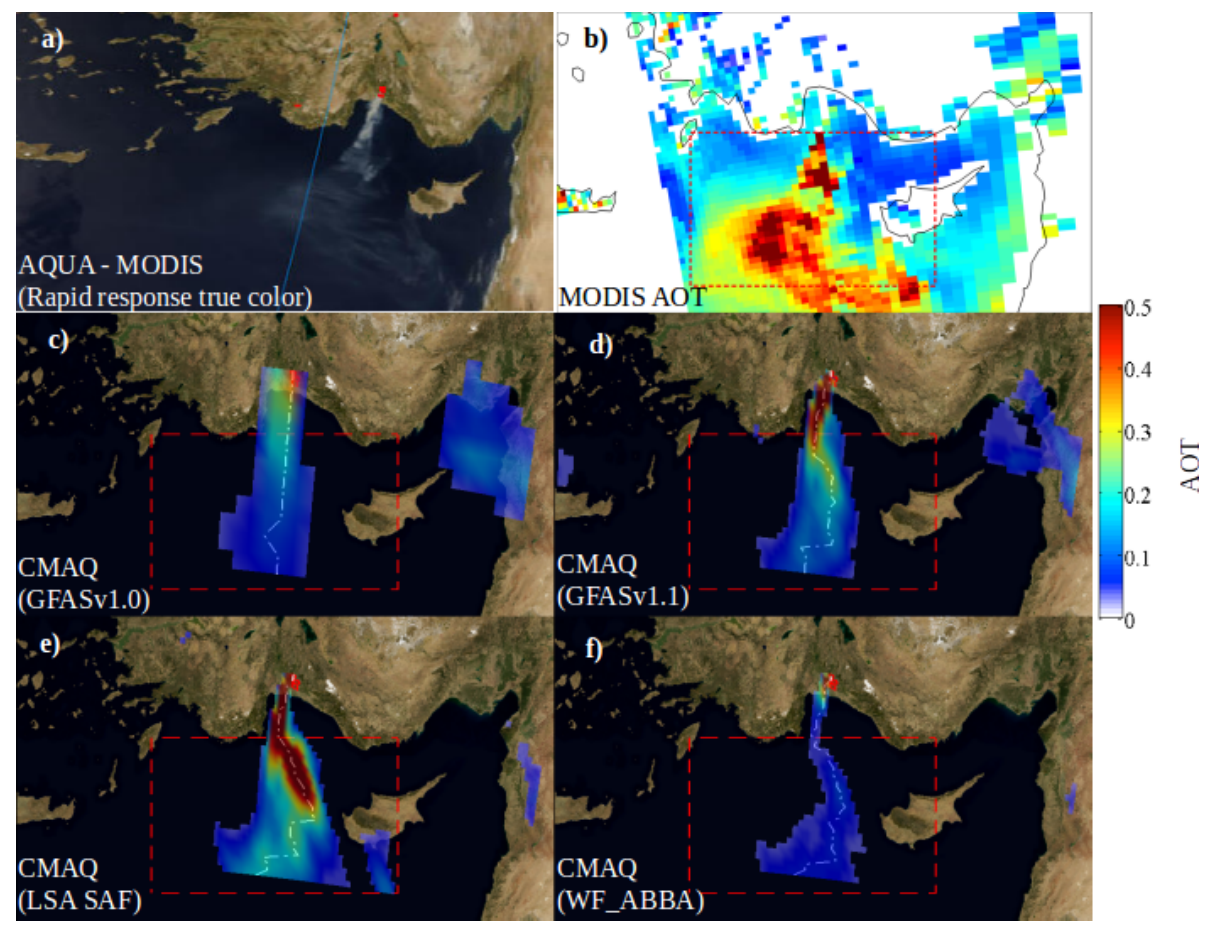

Figure 6. (a) MODIS (true color composite from visible wavelengths) over the eastern Mediterranean basin on 1 August 2008 at 14:30 LT. (b) Concurrent MODIS level 2 aerosol optical thickness. Concurrent CMAQ-simulated changes in AOT due to fires made by using GFAS1.0 (c), GFAS1.1 (d), LSA SAF-based (e) and WF_ABBA-based (f) fire emission inventories. The changes in the AOT are calculated by subtracting concentrations from simulations without fires. The white-dashed line connects the cells of the model grid having the maximum-simulated AOT along the Antalya fire plume. MODIS AOT color scale is the same as the one for the simulated changes in AOT.

the rest of the pixels, which are clean, resulting in a missing description of the first part of the Antalya fire plume.

In order to directly compare with the MODIS AOT, the model-simulated aerosol species (mostly $\mathrm{PM}_{2.5}$ ) mass concentrations are converted to AOT values. The latter has been calculated from model output according to Malm et al. (1994), where aerosol extinction depends on aerosol mass, scattering coefficients for different aerosol components, and an adjustment factor for relative humidity light scattering.

The simulated changes in AOT due to the smoke plume dispersion based on hourly estimates are shown in Fig. 6c for GFAS1.0, Fig. 6d for GFAS1.1, Fig. 6e for LSA SAF and Fig. 6f for WF_ABBA. (Animations covering 31 July to 2 August 2008 are available in the Supplement.) The changes in the AOT due to the fires are estimated by subtracting the AOT simulated without including the biomassburning emission inventory. The simulations performed with the four different fire emission inventories reproduce the observed plume features: an intense plume downwind of the fire, above the bay of Antalya, that broadens in the southern direction. But only the LSA SAF FRP-pixel-based emission inventory causes the plume to reach the southern west coast of Cyprus, as it does in the MODIS observations.

Figure 7 shows the vertical cross sections of the simulated changes in $\mathrm{PM}_{2.5}$ concentrations due to the different fire emission inventories, along with the maximum-simulated AOT (white-dashed lines in Fig. 6c-f).

Very high $\mathrm{PM}_{2.5}$ concentrations (around $200 \mu \mathrm{g} \mathrm{m}^{-3}$ ) above the PBL (black-dashed line in Fig. 7) are observed for the CMAQ simulation with the LSA SAF (Fig. 7c), while lower concentration are simulated with GFAS1.0, GFAS1.1 and WF_ABBA (Fig. 7a, b and d, respectively). This is a combined result of different emission magnitude, timing and injection height estimated by the four emission inventories.

In the presence of a large biomass-burning event, the vertical allocation of the fire emissions is an important parameter that can strongly determine the correct description of the spatiotemporal evolution of the fire plume. In fact, in this case the top plume height can strongly exceed the daily maximum of the boundary layer height and catch a completely different atmospheric dynamic.

During the first 2 days of the Antalya fire, only the LSA SAF FRP allows for strong concentrations of $\mathrm{PM}_{2.5}$ above $2000 \mathrm{~m}$ and it is the only one who depicted a cluster of aerosol moving toward southwest Cyprus, as confirmed by MODIS observations in Fig. 8. Probably, the higher vertical allocation of the emission estimated by LSA SAF FRP allows a part of the fire aerosols to catch a different wind dynamic in the upper atmospheric layers that leads them to 


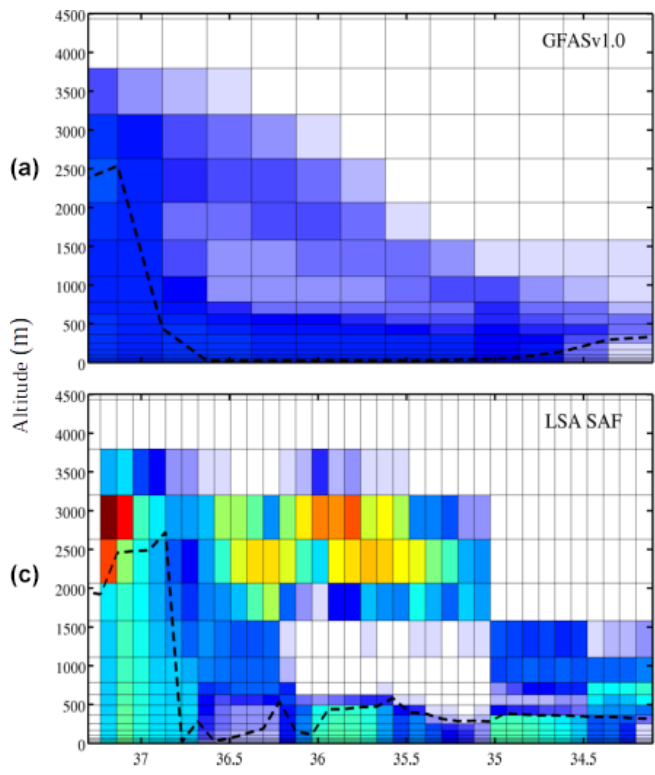

(b)

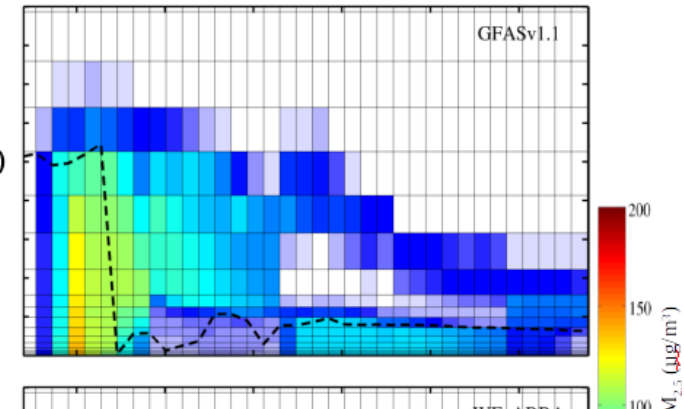

(d)

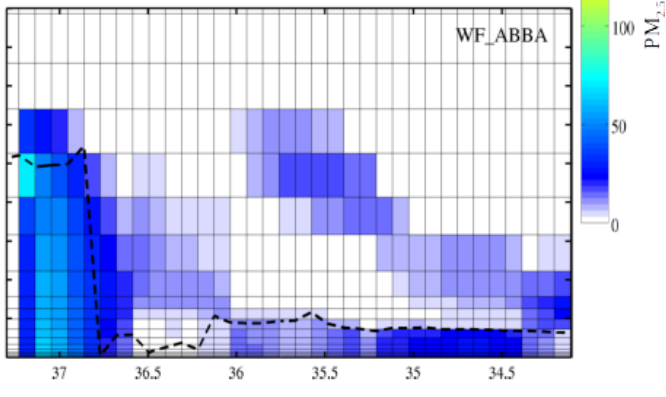

Latitude

Figure 7. On 1 August 2008 at 15:00 LT, vertical cross section, across the concurrent maximum-simulated AOT, showing the changes in the $\mathrm{PM}_{2.5}$ concentration across the main plume of Antalya fire for the CMAQ simulations performed with GFAS1.0 (a), GFAS1.1 (b), LSA SAF (c) and WF_ABBA-based (d) fire emission inventories. The changes in the $\mathrm{PM}_{2.5}$ concentration are calculated by subtracting concentrations from simulations without fires. The black-dashed line defines the PBL.

southeast as observed a few hours later in the MODIS observations (see also the animations in the Supplement).

\subsection{Top-down information on AOT}

Previous studies have found that the bottom-up estimate of aerosols tends to be underestimated by a factor of 3 due to uncertainties in input parameters for the emissions algorithm (Reid et al., 2009; Yang et al., 2011). In this study, we decided to boost our fire aerosol emission estimates (based on WF_ABBA and LSA SAF FRP) by a factor of 3.4 as suggested by Kaiser et al. (2012).

For the comparison with MODIS AOD, we selected the retrieved and simulated AOD data pairs from the same time and same location inside a selected area that includes the fire plume originating from Antalya (red-dashed box in Fig. 9).

From Fig. 9 we observe that point by point correlation is generally higher when the fire plume is not present in the selected area (30 July and 6 August 2008). In fact, if the magnitude or the spatiotemporal distribution of aerosol fire emission is poorly estimated, or if the transport and dispersion of fire plumes are not well represented in the CMAQ, the predicted fire plume at a certain location and time may not agree with the one observed by MODIS. For example, at 15:00 LT on 1 August, the largest AOD values associated with the fire plume, according to MODIS-Aqua retrievals, are located in the middle-left bottom part of the selected box, while the LSA SAF simulation from CMAQ shows larger AOD values in the middle-right upper part of the red box.
If we average MODIS and CMAQ data pairs over the selected red-dashed box, we can have an estimate of the performances of the different fire emission inventories in predicting the magnitude of the emitted smoke aerosols. In Fig. 10 we present the temporal series of the average AOT over the Antalya fire plume box, predicted by CMAQ and observed by MODIS from 30 July to 6 August 2008, and the corresponding correlations. In Figs. 9 and 10 we excluded MODIS observations with large areas of missing values inside the box surrounding the fire plume (the complete temporal series of the MODIS AOT from 30 July to 6 August 2008 is described Fig. S3 in the Supplement).

It is interesting that GFAS1.0 simulation shows the largest correlation coefficient $(0.72)$ even if the intensity and shape of the plume are not well represented, while the LSA SAF simulation shows the closest values in terms of AOT and plume shape, but only a correlation of 0.46 . This is mainly due to the observed MODIS AOD on the 4 August showing large AOT values east of Cyprus, which are captured 1 day in advance by the model simulations and, may indicate a problem in the model reproducing the plume transport in the last days of the fire.

By removing 4 August from the temporal series, we observe that the GFAS 1.0 and LSA SAF simulations are the more highly correlated with MODIS (Pearson's $R$ coefficient 0.79 and 0.77 , respectively). Also better correlation is observed with the GFAS1.1 and WF_ABBA FRP-based emission inventory (Pearson's $R$ coefficient 0.69 and 0.6 , respectively). 


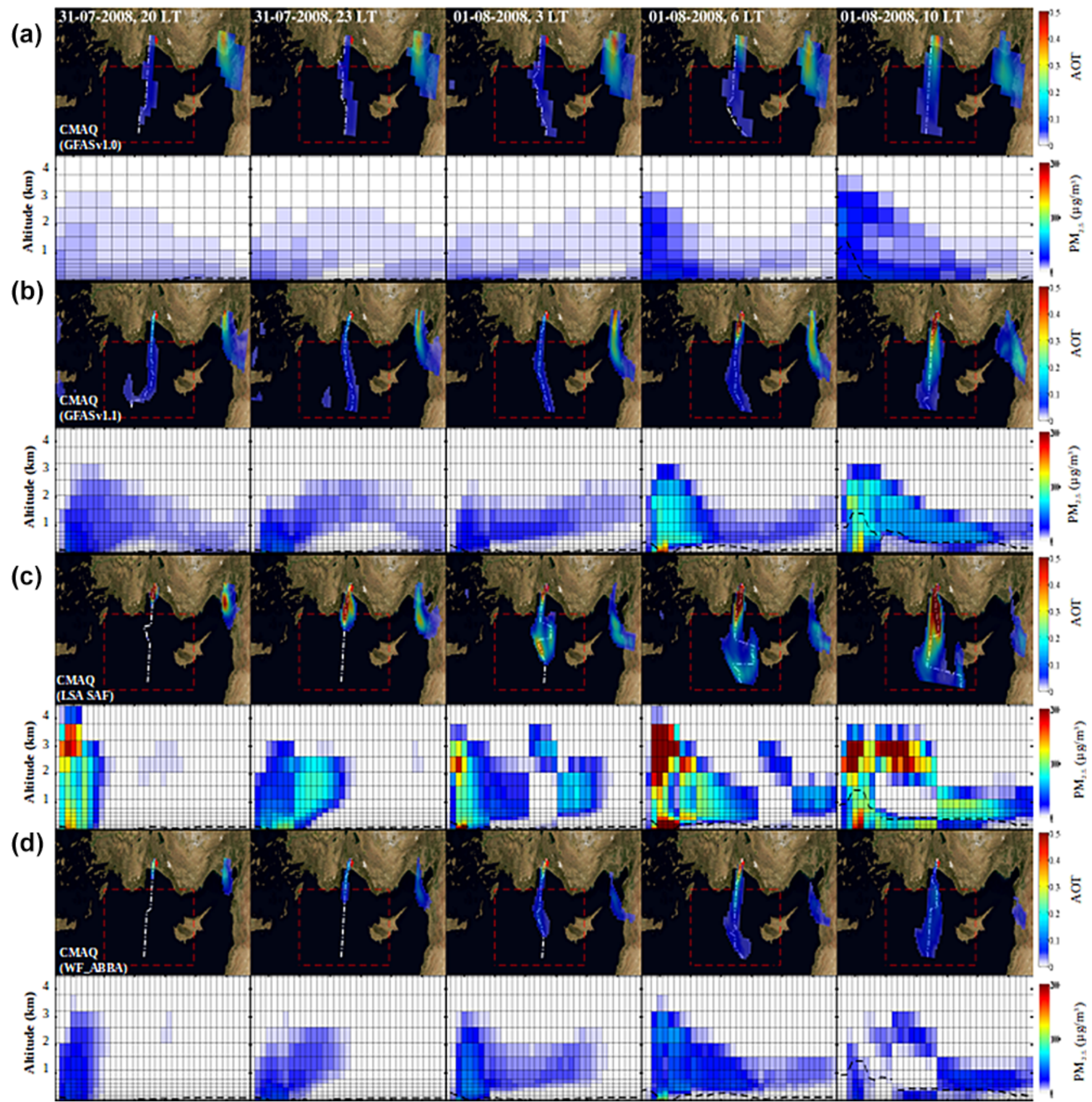

Figure 8. On 31 July 2008 at 20:00 LT, 31 July 2008 at 23:00 LT, 1 August 2008 at 03:00 LT, 1 August 2008 at 06:00 LT and 1 August 2008 at 10:00 LT. CMAQ-simulated changes in AOT and vertical distribution of fire $\mathrm{PM}_{2.5}$ concentration along the maximum-simulated AOT due to fires using GFAS1.0- (a), GFAS1.1- (b), LSA SAF- (c) and WF_ABBA-based (d) fire emission inventories. The changes in the AOT are calculated by subtracting concentrations from simulations without fires. The white-dashed line, in the AOT map, connects the cells of the model grid having the maximum-simulated AOD along the Antalya fire plume. Black-dashed line, in the vertical cross sections, defines the PBL. 

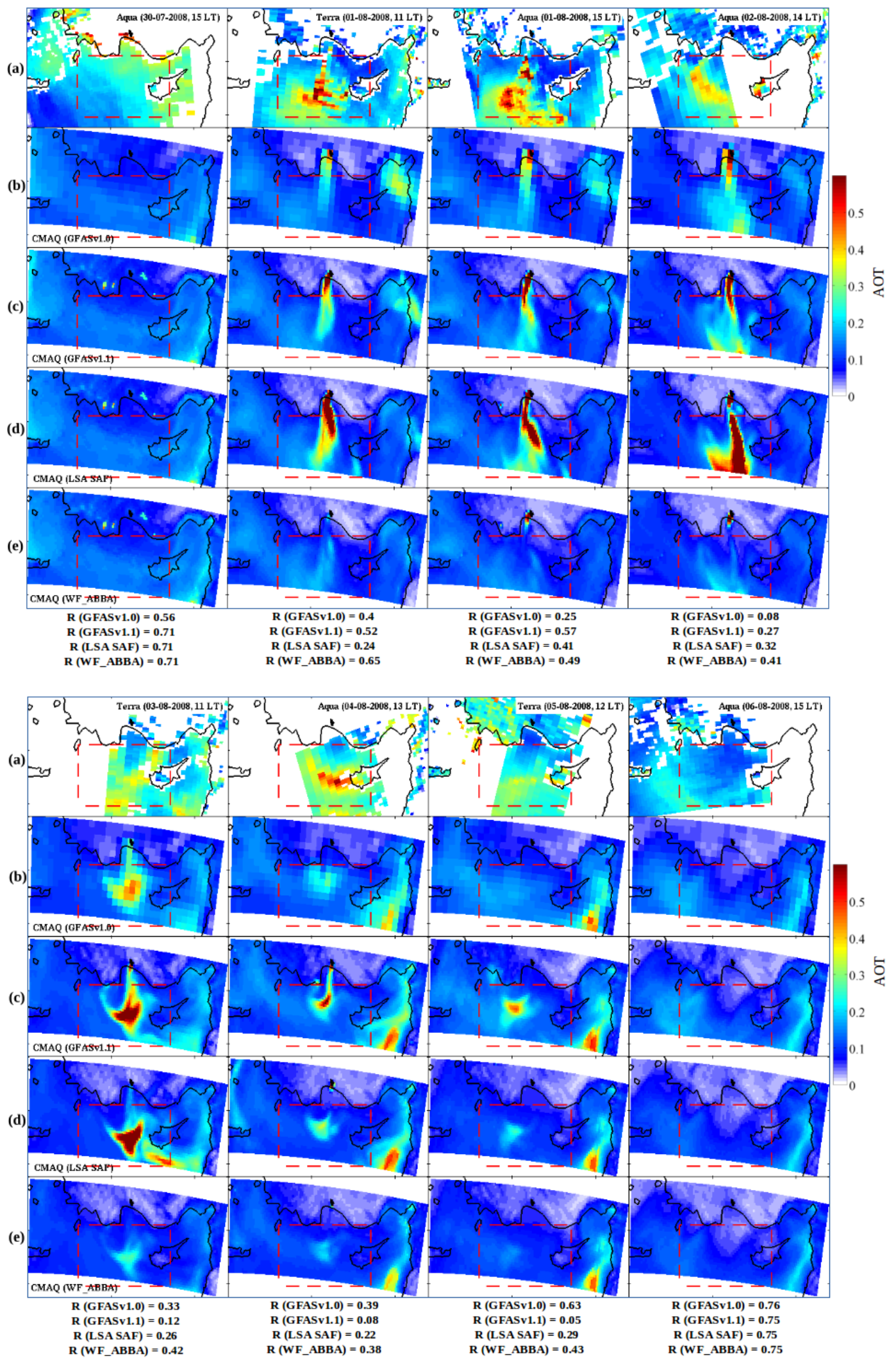

Figure 9. (a) Instantaneous MODIS AOT retrievals over the eastern Mediterranean basin from 30 July to 6 August 2008. Concurred CMAQsimulated AOT using GFAS1.0- (b), GFAS1.1- (c), LSA SAF- (d) and WF_ABBA-based (e) fire emission inventories. Pearson's R coefficients between MODIS observed and CMAQ-simulated AOT are given below. 
a)

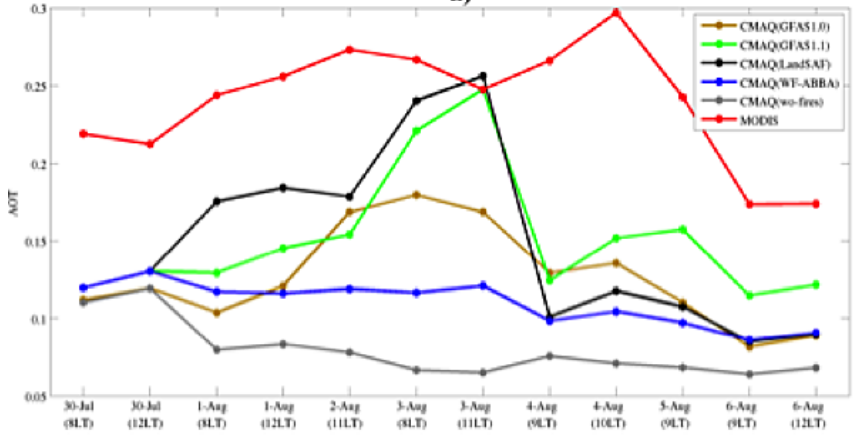

b)

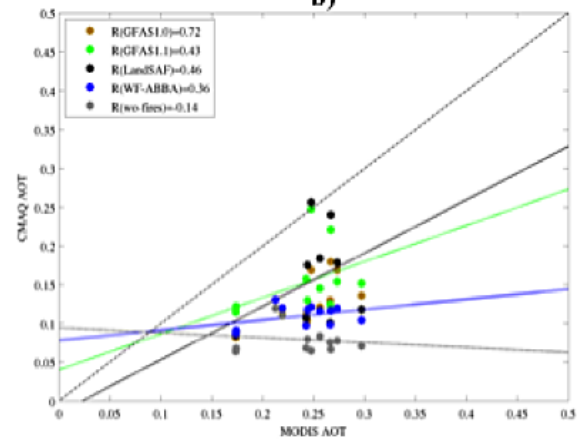

Figure 10. (a) Temporal variations of modeled and observed AOT from 30 July to 6 August 2008 averaged over the area of study and (b) linear regression and associated Pearson's $R$ coefficients between modeled and observed AOT averaged over the same period and area. Five different simulations have been performed using various emission scenarios: CMAQ (GFAS1.0), CMAQ (GFAS1.1), CMAQ (LSA SAF), CMAQ (WF_ABBA) and CMAQ (wo-fires) (without fires).

\subsection{Top-down information on total columns of $\mathrm{CO}$ and $\mathrm{NH}_{3}$}

We compared the CMAQ-simulated $\mathrm{CO}$ and $\mathrm{NH}_{3}$ total columns with IASI measurements. We considered for this purpose only simulated vertical columns at the same time and location as the IASI measurements inside a selected area that includes the fire plume originating from Antalya (red-dashed box in Fig. 10).

There is a good correlation between modeled and observed IASI CO total column averaged over the selected area for the LSA SAF (Pearson's $R$ coefficient 0.81 ) and the GFAS1.1 (Pearson's $R$ coefficients 0.57 ) simulations (Fig. 11). No correlation is observed between the WF_ABBA simulation and the observations (Pearson's $R$ coefficient -0.08 ); this could be explained by the lower estimation of the energy emitted by the Antalya fire (discussed in Sect. 3.1), which results in lower emission estimations. This can be seen in Fig. 11a, where CO total columns from the CMAQ (WF_ABBA) simulation are close to those without fires. Generally, the CMAQ simulations seem to underestimate the CO total columns except for the LSA SAF at high concentrations (Fig. 11).

A positive correlation is found between each individual CO IASI observation and the coincident $\mathrm{CO}$ modeled with the CMAQ simulation with the three different fire scenarios (Pearson's $R$ coefficients ranging from 0.38 to 0.91 ), except for 31 July PM data (Pearson's $R$ coefficients ranging from 0.15 to 0.23 ) (see Fig. 11). This implies that the CMAQ model provides a relatively accurate representation of the temporal pattern of the emission and transport in comparison to IASI.

IASI $\mathrm{NH}_{3}$ total column observations have a large relative error $(\geq 100 \%)$ for most of the measurements. This is due to relatively small $\mathrm{NH}_{3}$ total columns and low thermal contrasts above the sea (Van Damme et al., 2014), where most of the fire plume is located. Nevertheless, we observe a good correspondence between temporal variations of mod- eled and measured $\mathrm{NH}_{3}$ total columns averaged over the study area with average values of the same order of magnitude (Fig. 12), reaching $\approx 2 \times 10^{16}$ molecules $\mathrm{cm}^{-2}$ by IASI on 2 August AM.

\section{Summary and conclusions}

We explored the use of WF_ABBA and LSA SAF (MSGSEVIRI-based) FRP products to describe biomass-burning emissions of principal pollutants over the eastern Mediterranean during a strong wild fire event that occurred in southern Turkey in August 2008. We analyzed the estimates comparing them with the MODIS-based GFASv1.1 (Fig. 3 and Table 2).

The SEVIRI-based fire emission estimates are comparable with those from the GFASv1.1 when they describe the Antalya fire; for example, 2.3 and $10.9 \mathrm{Gg}$ of $\mathrm{PM}_{2.5}$ and 8.4 and $40.1 \mathrm{Gg}$ of $\mathrm{CO}$ are estimated for the entire Antalya episode from WF_ABBA and LSA SAF, while the GFASv1.1 based on MODIS estimates are 7.4 and $27.3 \mathrm{Gg}$ for $\mathrm{PM}_{2.5}$ and CO, respectively. However, WF_ABBA and LSA SAF tend to be quite lower when integrated over the entire Eastern Mediterranean basin. The presence of low energetic agricultural burning (common in Eastern Europe during summertime), undetected by SEVIRI because of its coarse spatial resolution, is probably the main cause of this difference.

Also the impact of the use of different conversion factors available in literature illustrates the large uncertainties of currently available biomass-burning emission estimates (Table 1).

The analysis of the CMAQ-simulated aerosol and trace gas transport from the Antalya fire shows the importance of a correct estimation of the emissions not only in terms of their magnitude but also in terms of emission timing and vertical distribution. The $\mathrm{PM}_{2.5}$ concentrations along the fire plume (Figs. 7 and 8) show that a better estimation of the plume 

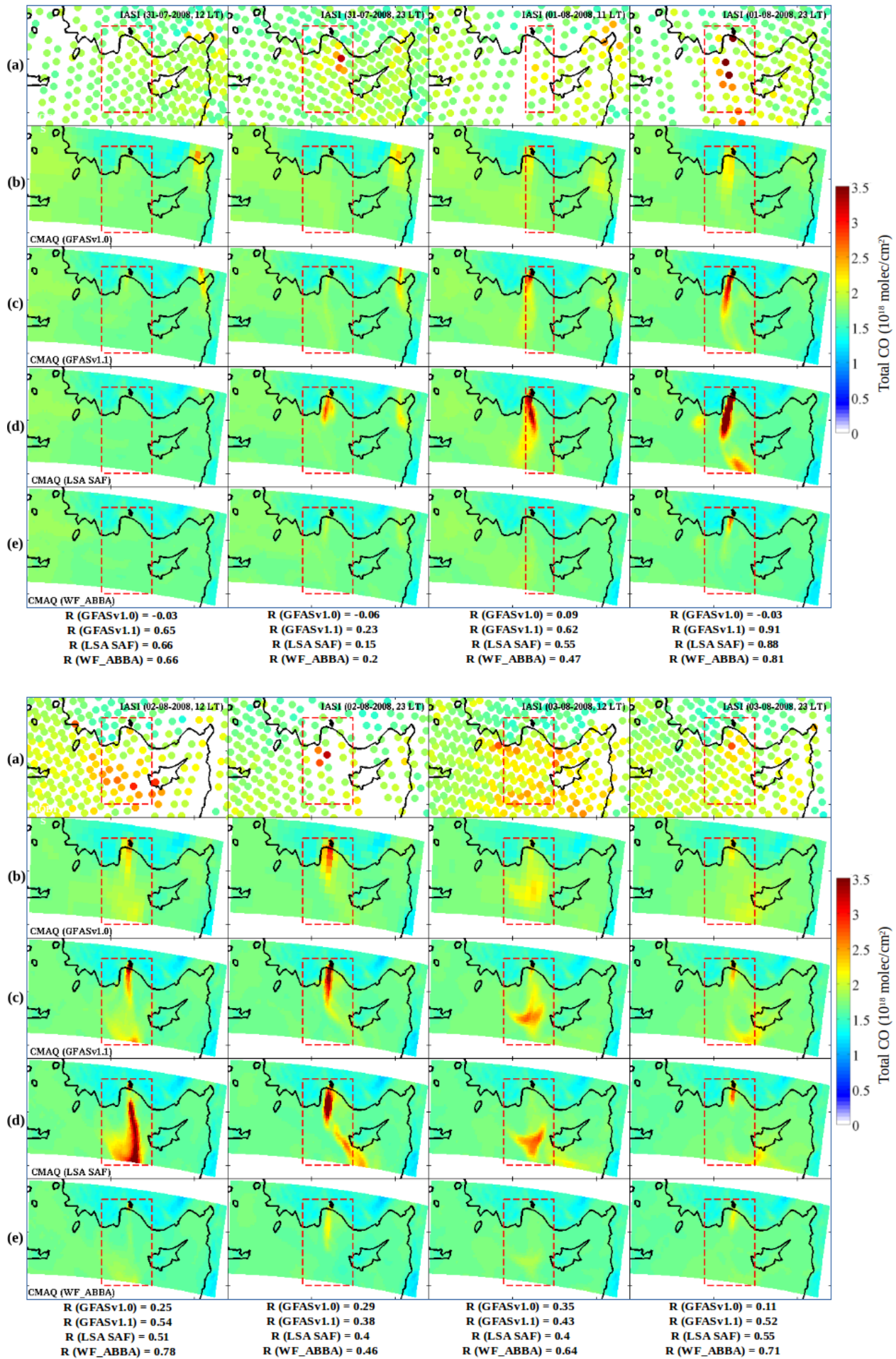

Figure 11. Daily AM and PM CO total column (molec $\mathrm{cm}^{-2}$ ) from top to bottom, using IASI, CMAQ(GFAS1.1), CMAQ(LSA SAF) and CMAQ(WF_ABBA) between 31 July 2008 and 3 August 2008 over the area of study. Pearson's $R$ coefficients between IASI CO and CMAQ $\mathrm{CO}$ simulations are given below. 

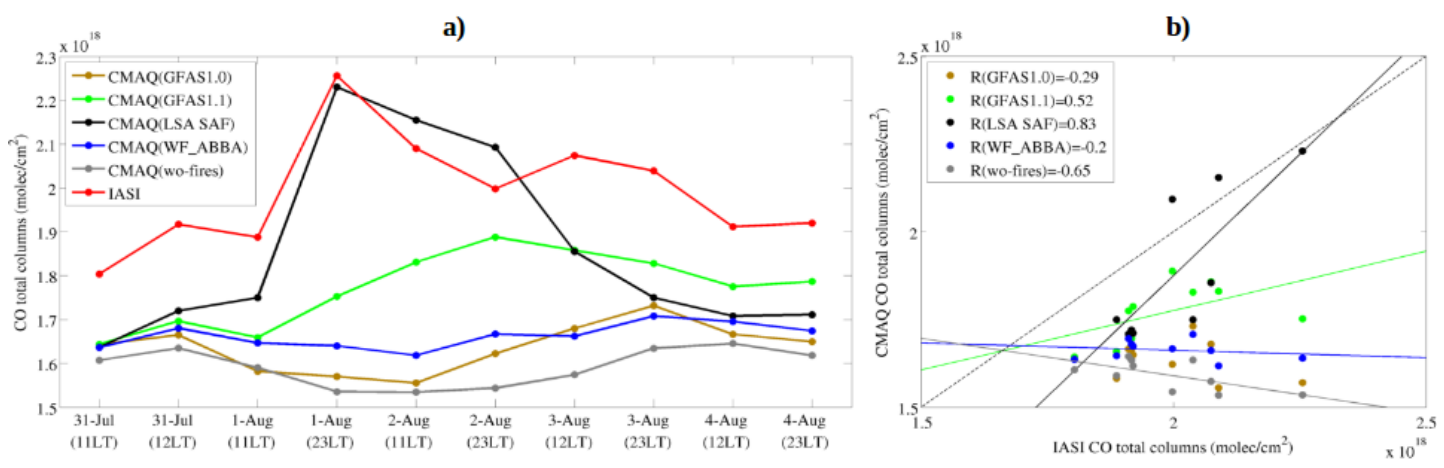

c)

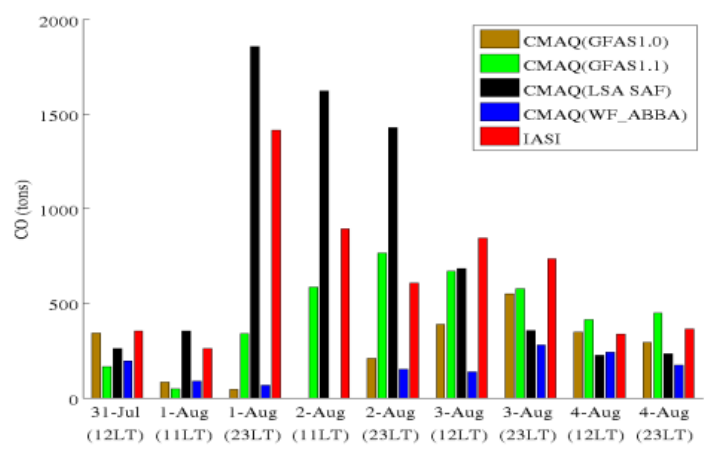

Figure 12. (a) Temporal variations of modeled and observed CO total columns from 31 July to 3 August 2008 averaged over the area of study and (b) linear regression and associated Pearson's $R$ coefficients between modeled and observed CO total columns averaged over the same period and area. (c) Tons of CO emitted by the Antalya fire over the study area, as observed by IASI and simulated by CMAQ. The contribution of the Antalya fire on the CO observed and simulated has been evaluated by subtracting the minimum value of the respective time series in the upper-left panel. Five different simulations have been performed using various emission scenarios: CMAQ (GFAS1.0), CMAQ (GFAS1.1), CMAQ (LSA SAF), CMAQ (WF_ABBA) and CMAQ (wo-fires) (without fires).

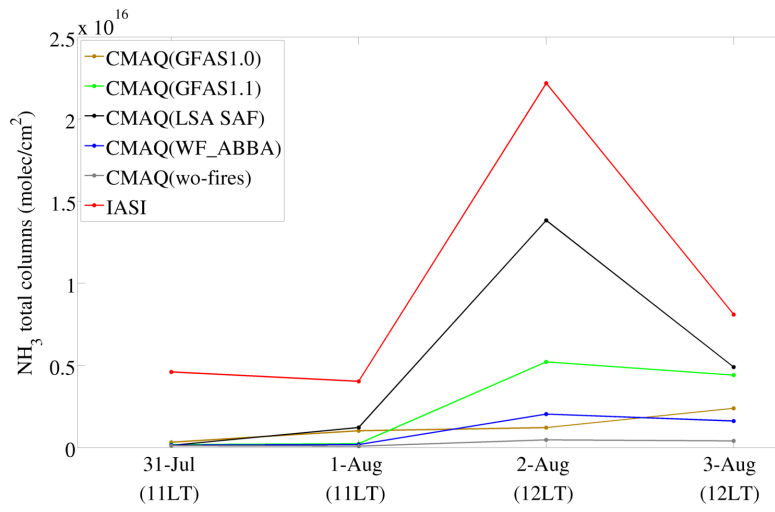

Figure 13. Temporal variations of modeled and observed $\mathrm{NH}_{3}$ total column from 31 July to 3 August 2008 averaged over the area of study. The averaged values are a mean of all measurements within the studied area, weighted by the relative retrieval error of ammonia measurements following Eq. (2).

penetration above the PBL (in the simulation performed with the LSA SAF-based emission inventory) led to a more accurate description of its subsequent features as confirmed by MODIS observations (Fig. 6).
In comparison with IASI total column $\mathrm{CO}$ and $\mathrm{NH}_{3}$, the simulations performed using GFASv1.1 and LSA SAF FRPpixel-based fire emission inventories provide a more accurate representation of the temporal pattern of emissions and transport, while that based on the WF_ABBA tends to underestimate the concentration of these species along the simulated fire plume.

The high correlation found between CMAQ simulation with LSA SAF-based emissions and IASI measurements (Fig. 12) shows that this data set provides the most accurate description of the emission emitted by Antalya fire both in terms of their magnitude and in terms of their spatiotemporal distribution.

We conclude that SEVIRI observations can refine biomass-burning emissions, which can subsequently be used in regional-scale air quality models like CMAQ to improve the prediction of the chemical composition of the atmosphere in the presence of large biomass-burning episodes.

Higher spatial resolution observations from a future imager in geostationary orbit would help to realize improved fire detection and characterization products of low energetic fire activity that would help to fill the temporal gap observed with available polar observations. 


\section{The Supplement related to this article is available online at doi:10.5194/acp-15-8539-2015-supplement.}

Acknowledgements. This research was supported by the Turkish Science Foundation via 111G037, "Development of Air Pollution Emissions Management System”.

The research in Belgium was funded by the F.R.S.-FNRS and the Belgian State Federal Office for Scientific, Technical and Cultural Affairs (prodex arrangement 4000111403). S. Whitburn is grateful to the "Fonds pour la Formation á la Recherche dans l'Industrie et dans l'Agriculture" for a PhD grant (Boursier FRIA). P.-F. Coheur is Senior Research Associate with F.R.S.-FNRS.

We gratefully acknowledge support from the projects "Effects of Climate Change on Air Pollution Impacts and Response Strategies for European Ecosystems" (ECLAIRE) and "Monitoring of Atmospheric Composition and Climate - Interim Implementation" (MACC-II), funded under the EC 7th Framework Programme (grant agreement nos. 282910 and 283576, respectively), as well as from the EUMETSAT SAF on Ozone and Atmospheric Chemistry Monitoring (O3MSAF).

We would like to thank Martin Wooster at Kings College London for helping us to describe in a clear and articulate manner the Meteosat fire radiative power-pixel product. G. Baldassarre would like to thank Elaine M. Prins, Jason C. Brunner and Jay P. Hoffman, members of the biomass-burning group at the Cooperative Institute for Meteorological Satellite Studies (CIMSS), and Jean M. Phillips at the Space Science and Engineering Center (SSEC) at the University of Wisconsin-Madison for their assistance, guidance and support.

Edited by: V.-H. Peuch

\section{References}

Andreae, M. O. and Merlet, P.: Emission of trace gases and aerosols from biomass burning, Global Biogeochem. Cy., 15, 955-966, doi:10.1029/2000gb001382, 2001

Calle, A., Casanova, J.-L., and Gonzalez-Alonso, F.: Impact of point spread function of MSG-SEVIRI on active fire detection, Int. J. Remote Sens., 30, 4567-4579, 2009.

Chen, F. and Dudhia, J.: Coupling an advanced land surfacehydrology model with the Penn State-NCAR MM5 modeling system. Part I: Model implementation and sensitivity, Mon. Weather Rev., 129, 569-585, 2001.

Clarisse, L., R'Honi, Y., Coheur, P.-F., Hurtmans, D., and Clerbaux, C.: Thermal infrared nadir observations of 24 atmospheric gases, Geophys. Res. Lett., 38, L10802+, doi:10.1029/2011g1047271, 2011.

Clerbaux, C., Boynard, A., Clarisse, L., George, M., Hadji-Lazaro, J., Herbin, H., Hurtmans, D., Pommier, M., Razavi, A., Turquety, S., Wespes, C., and Coheur, P.-F.: Monitoring of atmospheric composition using the thermal infrared IASI/MetOp sounder, Atmos. Chem. Phys., 9, 6041-6054, doi:10.5194/acp-9-6041-2009, 2009.
Coheur, P.-F., Clarisse, L., Turquety, S., Hurtmans, D., and Clerbaux, C.: IASI measurements of reactive trace species in biomass burning plumes, Atmos. Chem. Phys., 9, 5655-5667, doi:10.5194/acp-9-5655-2009, 2009.

Darmenov, A. and da Silva, A.: The Quick Fire Emissions Dataset (QFED) - Documentation of versions 2.1, 2.2 and 2.4, NASA Technical Report Series on Global Modeling and Data Assimilation, NASA Center for AeroSpace Information, Goddard Space Flight Center, Greenbelt, MD 20771, NASA TM-2013-104606, 32, 183, 2013.

Denier van der Gon, H., van het Bolscher, M., Visschedijk, A., and Zandveld, P.: Study to the effectiveness of the UNECE Heavy Metals Protocol and costs of possible additional measures Phase I: Estimation of emission reduction resulting from the implementation of the HM Protocol, Apeldoorn, the Netherlands, TNO (Netherlands Organisation for Applied Scientific Research), TNO Report B\&O-A R 2005, 193, 2005.

Dozier, J.: A method for satellite identification of surface temperature fields of subpixel resolution, Remote Sens. Environ., 11, 221-229, doi:10.1016/0034-4257(81)90021-3, 1981.

Dudhia, J.: Numerical study of convection observed during the winter monsoon experiment using a mesoscale two-dimensional model, J. Atmos. Sci., 46, 3077-3107, 1989.

Ellicott, E., Vermote, E., Giglio, L., and Roberts, G.: Estimating biomass consumed from fire using MODIS FRE, Geophys. Res. Lett., 36, L13401, doi:10.1029/2009GL038581, 2009.

Foley, K. M., Roselle, S. J., Appel, K. W., Bhave, P. V., Pleim, J. E., Otte, T. L., Mathur, R., Sarwar, G., Young, J. O., Gilliam, R. C., Nolte, C. G., Kelly, J. T., Gilliland, A. B., and Bash, J. O.: Incremental testing of the Community Multiscale Air Quality (CMAQ) modeling system version 4.7, Geosci. Model Dev., 3, 205-226, doi:10.5194/gmd-3-205-2010, 2010.

Garcia-Menendez, F., Hu, Y., and Odman, M. T.: Simulating smoke transport from wildland fires with a regional-scale air quality model: sensitivity to spatiotemporal allocation of fire emissions, Sci. Total Environ., 493, 544-553, 2014.

Govaerts, Y., Wooster, M., Lattanzio, A., and Roberts, G.: Fire Radiative Power (FRP) characterisation Algorithm Theoretical Basis Document: The EUMETSAT Network of Satellite Application Facilities Lisbon, Portugal, EUMETSAT, Tech. rep., EUM/MET/SPE/06/0398, 2007.

Guenther, A., Karl, T., Harley, P., Wiedinmyer, C., Palmer, P. I., and Geron, C.: Estimates of global terrestrial isoprene emissions using MEGAN (Model of Emissions of Gases and Aerosols from Nature), Atmos. Chem. Phys., 6, 3181-3210, doi:10.5194/acp-63181-2006, 2006.

Heil, A., Kaiser, J. W., van der Werf, G. R., Wooster, M. J., Schultz, M. G., and van der Gon, H. D.: Assessment of the RealTime Fire Emissions (GFASv0) by MACC, European Centre for Medium-Range Weather Forecasts, Reading, UK, 2010.

Hogrefe, C., Rao, S. T., Kasibhatla, P., Kallos, G., Tremback, C. J., Hao, W., Olerud, D., Xiu, A., McHenry, J., and Alapaty, K.: Evaluating the performance of regional-scale photochemical modeling systems: Part I - Meteorological predictions, Atmos. Environ., 35, 4159-4174, 2001.

Hong, S.-Y. and Lim, J.-O. J.: The WRF single-moment 6-class microphysics scheme (WSM6), J. Korean Meteor. Soc, 42, 129$151,2006$. 
Hong, S.-Y., Dudhia, J., and Chen, S.-H.: A revised approach to ice microphysical processes for the bulk parameterization of clouds and precipitation, Mon. Weather Rev., 132, 103-120, 2004.

Hurtmans, D., Coheur, P., Wespes, C., Clarisse, L., Scharf, O., Clerbaux, C., Hadji-Lazaro, J., George, M., and Turquety, S.: FORLI radiative transfer and retrieval code for IASI, J. Quant. Spectrosc. Ra., 113, 1391-1408, doi:10.1016/j.jqsrt.2012.02.036, 2012.

Ichoku, C. and Kaufman, Y.: A method to derive smoke emission rates from MODIS fire radiative energy measurements, IEEE T. Geosci. Remote, 43, 2636-2649, doi:10.1109/TGRS.2005.857328, 2005.

Im, U., Markakis, K., Unal, A., Kindap, T., Poupkou, A., Incecik, S., Yenigun, O., Melas, D., Theodosi, C., and Mihalopoulos, N.: Study of a winter PM episode in Istanbul using the high resolution WRF/CMAQ modeling system, Atmos. Environ., 44, 3085-3094, 2010.

Im, U., Markakis, K., Poupkou, A., Melas, D., Unal, A., Gerasopoulos, E., Daskalakis, N., Kindap, T., and Kanakidou, M.: The impact of temperature changes on summer time ozone and its precursors in the Eastern Mediterranean, Atmos. Chem. Phys., 11, 3847-3864, doi:10.5194/acp-11-3847-2011, 2011.

Inness, A., Baier, F., Benedetti, A., Bouarar, I., Chabrillat, S., Clark, H., Clerbaux, C., Coheur, P., Engelen, R. J., Errera, Q., Flemming, J., George, M., Granier, C., Hadji-Lazaro, J., Huijnen, V., Hurtmans, D., Jones, L., Kaiser, J. W., Kapsomenakis, J., Lefever, K., Leitão, J., Razinger, M., Richter, A., Schultz, M. G., Simmons, A. J., Suttie, M., Stein, O., Thépaut, J.-N., Thouret, V., Vrekoussis, M., Zerefos, C., and the MACC team: The MACC reanalysis: an $8 \mathrm{yr}$ data set of atmospheric composition, Atmos. Chem. Phys., 13, 4073-4109, doi:10.5194/acp-13-4073-2013, 2013.

JRC: Forest Fires in Europe 2007. JRC Scientific and Technical Reports, Tech. Rep. EUR 23492, Joint Research Centre, Ispra, Italy., available at: http://forest.jrc.ec.europa.eu/media/cms_ page_media/9/forest-fires-in-europe-2008.pdf (last access: 25 September 2014), 2008.

JRC: Forest Fires in Europe 2008. JRC Scientific and Technical Reports, Tech. Rep. EUR 23971, Joint Research Centre, Ispra, Italy, available at: http://forest.jrc.ec.europa.eu/media/cms_ page_media/9/forest-fires-in-europe-2009.pdf (last access: 30 September 2014), 2009.

Kain, J. S.: The Kain-Fritsch convective parameterization: an update, J. Appl. Meteorol., 43, 170-181, 2004.

Kaiser, J. W., Boucher, O., Doutriaux-Boucher, M., Flemming, J., GOVAERTS, Y. M., Gulliver, J., Heil, A., Jones, L., Lattanzio, A., Morcrette, J.-J., Perrone, M. R., Razinger, M., Roberts, G., Schultz, M. G., Simmons, A. J., Suttie, M., and Wooster, M. J.: Smoke in the air, ECMWF Newsletter, 119, 9-15, 2009.

Kaiser, J. W., Heil, A., Andreae, M. O., Benedetti, A., Chubarova, N., Jones, L., Morcrette, J.-J., Razinger, M., Schultz, M. G., Suttie, M., and van der Werf, G. R.: Biomass burning emissions estimated with a global fire assimilation system based on observed fire radiative power, Biogeosciences, 9, 527-554, doi:10.5194/bg-9-527-2012, 2012.

Kavgac1, A., Čarni, A., Başaran, S., Başaran, M. A., Košir, P., Marinšek, A., and Šilc, U.: Long-term post-fire succession of Pinus brutia forest in the east Mediterranean, Int. J. Wildland Fire, 19, 599-605, 2010.
Kelly, J. T., Bhave, P. V., Nolte, C. G., Shankar, U., and Foley, K. M.: Simulating emission and chemical evolution of coarse seasalt particles in the Community Multiscale Air Quality (CMAQ) model, Geosci. Model Dev., 3, 257-273, doi:10.5194/gmd-3257-2010, 2010.

Kindap, T., Unal, A., Chen, S.-H., Hu, Y., Odman, M., and Karaca, M.: Long-range aerosol transport from Europe to Istanbul, Turkey, Atmos. Environ., 40, 3536-3547, 2006.

Konovalov, I. B., Berezin, E. V., Ciais, P., Broquet, G., Beekmann, M., Hadji-Lazaro, J., Clerbaux, C., Andreae, M. O., Kaiser, J. W., and Schulze, E.-D.: Constraining $\mathrm{CO}_{2}$ emissions from open biomass burning by satellite observations of co-emitted species: a method and its application to wildfires in Siberia, Atmos. Chem. Phys., 14, 10383-10410, doi:10.5194/acp-14-10383-2014, 2014.

Laneve, G., Castronuovo, M. M., and Cadau, E. G.: Continuous monitoring of forest fires in the Mediterranean area using MSG, IEEE T. Geosci. Remote, 44, 2761-2768, 2006.

Lattanzio, A., Wooster, M., and Freeborn, P.: LSA SAF Product User Manual: FRP, The EUMETSAT Network of Satellite Application Facilities, Lisbon, Portugal, 2009.

Levy, R. C., Remer, L. A., Mattoo, S., Vermote, E. F., and Kaufman, Y. J.: Second-generation operational algorithm: retrieval of aerosol properties over land from inversion of Moderate Resolution Imaging Spectroradiometer spectral reflectance, J. Geophys. Res.-Atmos., 112, D13211, doi:10.1029/2006JD007811, 2007.

Malm, W. C., Sisler, J. F., Huffman, D., Eldred, R. A., and Cahill, T. A.: Spatial and seasonal trends in particle concentration and optical extinction in the United States, J. Geophys. Res.Atmos., 99, 1347-1370, 1994.

Migliavacca, M., Dosio, A., Camia, A., Hobourg, R., HoustonDurrant, T., Kaiser, J. W., Khabarov, N., Krasovskii, A. A., Marcolla, B., Miguel-Ayanz, S., Ward, D. S., and Cescatti, A.: Modeling biomass burning and related carbon emissions during the 21st century in Europe, J. Geophys. Res.-Biogeo., 118, 17321747, 2013.

Mlawer, E. J., Taubman, S. J., Brown, P. D., Iacono, M. J., and Clough, S. A.: Radiative transfer for inhomogeneous atmospheres: RRTM, a validated correlated-k model for the longwave, J. Geophys. Res.-Atmos., 102, 16663-16682, 1997.

Morcrette, J. J., Jones, L., Kaiser, J., Benedetti, A., and Boucher, O.: Toward a forecast of aerosols with the ECMWF Integrated Forecast System, ECMWF Newsl, 114, 15-17, 2007.

Odman, M. T., Hu, Y., Unal, A., Russell, A. G., and Boylan, J. W.: Determining the sources of regional haze in the southeastern United States using the CMAQ model, J. Appl. Meteorol. Clim., 46, 1731-1743, 2007.

Otte, T. L. and Pleim, J. E.: The Meteorology-Chemistry Interface Processor (MCIP) for the CMAQ modeling system: updates through MCIPv3.4.1, Geosci. Model Dev., 3, 243-256, doi:10.5194/gmd-3-243-2010, 2010.

Poupkou, A., Markakis, K., Liora, N., Giannaros, T., Zanis, P., Im, U., Daskalakis, N., Myriokefal- itakis, S., Kaiser, J., Melas, D., Kanakidou, M., Karacostas, T., and Zerefos, C.: A modeling study of the impact of the 2007 Greek forest fires on the gaseous pollutant levels in the Eastern Mediterranean, Atmos. Res., 148, 1-17, doi:10.1016/j.atmosres.2014.05.015, 2014.

Prins, E.: Overview of current and future diurnal active fire monitoring using a suite of international geostationary satellites, Global and Regional Wildfire Monitoring: Current Status and 
Future Plans, edited by: Ahern, F. J., Goldammer, J. G., and Justice, C. O., SPB Acad., The Hague, the Netherlands, 145-170, 2001.

Prins, E. M. and Menzel, W.: Geostationary satellite detection of bio mass burning in South America, Int. J. Remote Sens., 13, 2783-2799, 1992.

Prins, E. M. and Menzel, W. P.: Trends in South American biomass burning detected with the GOES visible infrared spin scan radiometer atmospheric sounder from 1983 to 1991, J. Geophys. Res.-Atmos., 99, 16719-16735, 1994.

Reid, J. S., Hyer, E. J., Prins, E. M., Westphal, D. L., Zhang, J., Wang, J., Christopher, S. A., Curtis, C. A., Schmidt, C. C., and Eleuterio, D. P.: Global monitoring and forecasting of biomassburning smoke: Description of and lessons from the Fire Locating and Modeling of Burning Emissions (FLAMBE) program, Selected Topics in Applied Earth Observations and Remote Sensing, IEEE J., 3, 144-162, 2009.

Remer, L. A., Kaufman, Y., Tanré, D., Mattoo, S., Chu, D., Martins, J. V., Li, R.-R., Ichoku, C., Levy, R., Kleidman, R., Eck, T. F., Vermote, E., and Holben, B. N.: The MODIS aerosol algorithm, products, and validation, J. Atmos. Sci., 62, 947-973, 2005.

Roberts, G. J. and Wooster, M. J.: Fire detection and fire characterization over Africa using Meteosat SEVIRI, IEEE Trans. Geosci. Remote Sens., 46, 1200-1218, doi:10.1109/TGRS.2008.915751, 2008.

Roberts, G., Wooster, M. J., Perry, G. L., Drake, N., Rebelo, L.-M., and Dipotso, F.: Retrieval of biomass combustion rates and totals from fire radiative power observations: application to southern Africa using geostationary SEVIRI imagery, J. Geophys. Res.Atmos., 110, D21111, doi:10.1029/2005JD006018, 2005.

Roberts, G., Wooster, M. J., and Lagoudakis, E.: Annual and diurnal african biomass burning temporal dynamics, Biogeosciences, 6 , 849-866, doi:10.5194/bg-6-849-2009, 2009.

Roberts, G., Wooster, M. J., Xu, W., Freeborn, P. H., Morcrette, J.-J., Jones, L., Benedetti, A., and Kaiser, J.: LSA SAF Meteosat FRP Products: Part 2 - Evaluation and demonstration of use in the Copernicus Atmosphere Monitoring Service (CAMS), Atmos. Chem. Phys. Discuss., 15, 15909-15976, doi:10.5194/acpd-15-15909-2015, 2015.

Rodgers, C. D.: Inverse Methods for Atmospheric Sounding: Theory and Practice, vol. 2, World Scientific, Singapore, 2000.

Schultz, M. and Wooster, M.: Evaluation of a fire radiative power product derived from Meteosat 8/9 and identification of operational user needs, Final report to EUMETSAT contract, Jülich, Forschungszentrum Jülich, Zentralbibliothek, 2008.

Sifakis, N. I., Iossifidis, C., Kontoes, C., and Keramitsoglou, I.: Wildfire detection and tracking over Greece using MSG-SEVIRI satellite data, Remote Sens., 3, 524-538, 2011.

Skamarock, W. C. and Klemp, J. B.: A time-split nonhydrostatic atmospheric model for weather research and forecasting applications, J. Comp. Phys., 227, 3465-3485, 2008.

Sofiev, M., Vankevich, R., Lotjonen, M., Prank, M., Petukhov, V., Ermakova, T., Koskinen, J., and Kukkonen, J.: An operational system for the assimilation of the satellite information on wildland fires for the needs of air quality modelling and forecasting, Atmos. Chem. Phys., 9, 6833-6847, doi:10.5194/acp-9-68332009, 2009.
Sofiev, M., Ermakova, T., and Vankevich, R.: Evaluation of the smoke-injection height from wild-land fires using remote-sensing data, Atmos. Chem. Phys., 12, 1995-2006, doi:10.5194/acp-12-1995-2012, 2012.

Stoyanova, J., Georgiev, C., Yordanova, D., and Mladenov, K.: Active fire monitoring over Bulgaria: validation of SEVIRI FIR product, in: EUMETSAT Meteorological Satellite Conference, Darmstadt, Germany, 8-12, 2008.

Tolika, C., Zanis, P., and Anagnostopoulou, C.: Regional climate change scenarios for Greece: future temperature and precipitation projections from ensembles of RCMs, Global NEST J., 14, 407-421, 2012.

Turquety, S., Hurtmans, D., Hadji-Lazaro, J., Coheur, P.-F., Clerbaux, C., Josset, D., and Tsamalis, C.: Tracking the emission and transport of pollution from wildfires using the IASI CO retrievals: analysis of the summer 2007 Greek fires, Atmos. Chem. Phys., 9, 4897-4913, doi:10.5194/acp-9-4897-2009, 2009.

Unal, A., Hu, Y., Chang, M. E., Talat Odman, M., and Russell, A. G.: Airport related emissions and impacts on air quality: application to the Atlanta International Airport, Atmos. Environ., 39, 5787-5798, 2005.

Van Damme, M., Clarisse, L., Heald, C. L., Hurtmans, D., Ngadi, Y., Clerbaux, C., Dolman, A. J., Erisman, J. W., and Coheur, P. F.: Global distributions, time series and error characterization of atmospheric ammonia $\left(\mathrm{NH}_{3}\right)$ from IASI satellite observations, Atmos. Chem. Phys., 14, 2905-2922, doi:10.5194/acp-14-29052014, 2014.

Walker, J. C., Dudhia, A., and Carboni, E.: An effective method for the detection of trace species demonstrated using the MetOp Infrared Atmospheric Sounding Interferometer, Atmos. Meas. Tech., 4, 1567-1580, doi:10.5194/amt-4-1567-2011, 2011.

Wooster, M. J., Zhukov, B., and Oertel, D.: Fire radiative energy for quantitative study of biomass burning: derivation from the BIRD experimental satellite and comparison to MODIS fire products, Remote Sens. Environ., 86, 83-107, 2003.

Wooster, M. J., Roberts, G., Freeborn, P. H., Xu, W., Govaerts, Y., Beeby, R., He, J., Lattanzio, A., and Mullen, R.: Meteosat SEVIRI Fire Radiative Power (FRP) products from the Land Surface Analysis Satellite Applications Facility (LSA SAF) Part 1: Algorithms, product contents and analysis, Atmos. Chem. Phys. Discuss., 15, 15831-15907, doi:10.5194/acpd-15-158312015, 2015.

Yang, E.-S., Christopher, S. A., Kondragunta, S., and Zhang, X.: Use of hourly Geostationary Operational Environmental Satellite (GOES) fire emissions in a Community Multiscale Air Quality (CMAQ) model for improving surface particulate matter predictions, J. Geophys. Res.-Atmos., 116, D04303, doi:10.1029/2010JD014482, 2011.

Yarwood, G., Rao, S., Yocke, M., and Whitten, G.: Updates to the Carbon Bond Chemical Mechanism: CB05, Final Report to the US EPA, RT-0400675, available at: http://www.camx.com/ publ/pdfs/cb05_final_report_120805.pdf (last access: 16 December 2014), 2005 . 